\title{
Horizontal collaboration in the freight transport sector: barrier and decision-making frameworks
}

\author{
Ahmed Karam ${ }^{1,2^{*}} \mathbb{D}$, Kristian Hegner Reinau ${ }^{1}$ and Christian Richter Østergaard ${ }^{3}$
}

\begin{abstract}
In the freight transport sector, competing companies horizontally collaborate through establishing Collaborative Transport Networks (CTNs). Fruitful implementation of CTNs will leverage environmental and socio-economic goals of sustainable development in the freight transport sector. The benefits of CTNs in horizontal collaborative settings have been widely demonstrated through several modelling approaches. However, in practice, the real applications of CTNs have been challenging and most did not achieve satisfactory performances. Some studies have addressed this issue by identifying different barriers to CTN implementation. However, a conceptual framework for the barriers is not well-established. In addition, the literature lacks a decision-making framework for the CTN implementation which considers the different barriers. To address this gap, this paper conducted a literature review of the barriers to CTN implementation. In total, 31 different barriers were identified. A conceptual barrier framework is developed by grouping the 31 barriers into five categories: the business model, information sharing, the human factors, the Collaborative Decision Support Systems (CDSSs), and the market. The paper additionally proposes a stage-gate model integrating the conceptual barrier framework into the CTN implementation decision-making process. The current work contributes to the existing literature by developing both theoretical and practical understandings of the barriers to implementing CTNs and will support decision makers in CTN implementation to maximize the CTN benefits and minimize the risk of CTN failure.
\end{abstract}

Keywords: Horizontal collaboration, Freight, Barriers, Real application, Transport, Decision-making, Stage-gate model

\section{Introduction}

In the freight transport sector, the high market fragmentation has caused a serious problem of inefficient transport planning and empty running, leading to negative consequences such as increased delivery costs and environmental impacts, e.g., carbon emissions, road accidents, and noise. In 2018, $12.3 \%$ of the total distance made by freight trucks between EU countries was empty running while this percentage reached between 15 and 30\% inside some European countries [1]. Many

\footnotetext{
*Correspondence: akam@build.aau.dk; ahmed.mustafa@feng.bu.edu.eg

${ }^{1}$ Department of the Built Environment, Aalborg University, Aalborg, Denmark

Full list of author information is available at the end of the article
}

governments have recently set a long-term goal to make the freight transport sector more sustainable. Several studies showed that collaboration among companies on their transport activities can help achieve this goal and also enable lower delivery costs [2], fewer carbon emissions [3], increased service levels [4]. Some research projects and start-ups have been recently received public funding, aiming to encourage collaborative practices in the freight transport sector among shippers, carriers, and receivers (e.g., retailers) [5]. For instance, the CTN 'Nistevo' reported that two big shippers through collaboration could achieve savings of $19 \%$ in transport costs compared to the non-collaborative practice [6].

The present paper focuses on the horizontal transport collaboration in which a group of competing companies, 
i.e. shippers, carriers, or receivers, agrees to collaborate on their freight transport activities [7]. This is named as a Collaborative Transport Networks (CTNs). In most collaborative scenarios, collaborating companies (partners) are required to share the information on their transport orders and delivery trucks with a central coordinator, e.g., a logistics service provider. The central coordinator then uses the shared information to identify opportunities for collaboration, develop a joint delivery plan, or suggest freight exchanges among partners. Due to the huge amount of shared information and the need for efficient decisions, the coordinator often uses CDSSs to plan the collaboration processes [8]. The difference between transport costs in collaborative and non-collaborative settings is known as collaboration profits that the CDSSs might allocate among partners using various profit-sharing mechanisms [9].

Despite the extensively reported benefits of collaborative transport and the government funds to encourage the uptake of CTNs, their real applications have been rare and some CTNs were formed but did not last for a long time or did not achieve satisfactory performances [1014]. Recent studies suggest that the decision to implement CTNs should not be made without analyzing the many barriers to implementing CTNs. For example, Pan et al. [7] discussed the implementation barriers of CTNs with respect to the design and management of the CTN, CDSSs, and communications technology. More recently, Basso et al. [12] identified 16 barriers and further classified them into design, organization, information sharing, profit allocations, and human factors. Despite their merit, these studies have not provided a wider perspective of the barriers by considering specific CTN solutions and/or have not mentioned some important barriers, e.g., the barriers related to the CTN business model. Knowledge of these barriers is of great value since the failure or limited success of CTNs can be strongly attributed to the fundamentals of the business model [15-17]. In addition, these studies as well as exiting literature rarely identified a framework that systematically guides the decisions to implement the CTN with consideration to barriers.

The present paper makes two main contributions to the CTN implementation discourse. The first contribution is a conceptual framework for the barriers to implementing CTNs while the second is a decision-making model to guide the CTN implementation process with considerations to the identified barriers. The findings have valuable implications on theoretical and practical levels. Theoretically, it extends the existing classification of barriers into five groups: business model, information sharing, human factors, CDSSs, and market. This constitutes a better framework than analyzing the barriers on their own, as most of the existing studies did. The present paper performed a comprehensive literature review and identified 31 barriers while existing review studies identify a maximum of 16 barriers. Practically, the conceptual framework, as well as the decision-making model, will be useful to logistics service providers, freight carriers, logistics IT developers, researchers, decision makers in the logistics industry, funding organizations, and entrepreneurs in making decisions to implement collaborative freight transport. Furthermore, the identified barriers represent a valuable checklist for any CTN implementation and future research.

\section{Overview of horizontal collaboration in freight transport}

Collaboration is an old practice in the supply chain and can be mainly classified into vertical and horizontal collaboration. Vertical collaboration involves companies working at different levels of the supply chain, e.g., shipper-carrier collaboration [18] while horizontal collaboration involves companies working at the same level of the supply chain. The present paper focuses on the horizontal collaboration that can be applied through CTNs involving competing companies. To update the transport research field with a rich set of CTN barriers, the current work considers different CTN solutions found in the literature and categorizes them into three CTN types similar to $[19,20]$ as follows:

- An open electronic marketplace platform enables companies to build a temporary CTN in the spot market and is often executed without formal documentation. E-marketplace platforms are applied as a web-based information system and connect different companies, i.e. shippers, carriers, and LSPs, that might not have collaborated before. In E-marketplace, competing companies can build horizontal transport collaboration, for example, the Nistevo platform facilitates shipper collaboration by consolidating loads into full truckloads [21]. Another wellknown example is TIMOCOM [22].

- A strategic alliance is a CTN based on a long-term partnership and contractual agreements among companies [7]. For example, transport alliances might be formed by a group of small carriers to achieve economies of scale through serving transport demands from many small shippers or a few large shippers [23]. The formation of transport alliances requires making strategic decisions (e.g., partner selection), tactical decisions (e.g., cost and profit sharing), and operational decisions (e.g., collaborative vehicle routing and order sharing decisions). In horizontal collaboration, transport and logistics alliances might include two or more competing companies, e.g., 
shippers, logistics service providers (LSPs), carriers, or receivers. Thus, there exist carrier alliances, shipper alliances, retailer alliances, and LSP alliances [7, 19]. The shippers are those companies existing at the origin of a delivery. In shipper alliances, two or more shippers, e.g., raw material suppliers or manufacturers, agree to use one logistics service provider or carrier to reduce their transport and logistics costs, see for example [24]. The retailers are mostly considered as the final destination of the products [25]. In retailer alliances, two or more retailers use the same logistics service provider or one carrier [26]. Carriers are companies that perform deliveries among shippers and receivers. In carrier alliances, two or more carriers consolidate their freight in a few trucks, aiming to use fewer trucks and accordingly, reduce delivery costs and negative externalities [27]. Finally, LSPs are companies that manage the whole supply chain of different companies. Since LSPs act as interfaces between carriers, shippers, and receivers, they have an essential role in many collaborative logistics initiatives [19]. Moreover, partners of the alliance might collaborate on transport activities within longdistance transport or urban transport. However, both long-distance and urban transport alliances face similar organizational and technological challenges [20].

- Urban Consolidation Centers (UCCs) have been most frequently considered as a CTN to solve city logistics problems [20]. The idea of UCC is to replace multiple last-mile delivery movements with a common receiving facility, i.e. the consolidation center, where deliveries are sorted and consolidated in a small freight vehicle. For example, a group of retailers can perform last-mile deliveries from a UCC to their end customers in urban regions [26].

All CTN solutions require the use of CDSSs for information sharing and efficiently developing collaborative plans. Figure 1 shows the basic structure of the CDSS including three major modules, i.e. database, computational algorithms, and an interactive dialog. The database module receives and stores all logistics information to be fed into the algorithmic module either by manual entry or automatic feeding from partners' transport planning systems. The algorithmic module is responsible for processing the shared information and planning the collaborative decisions, e.g., exchange proposals and profit allocation among partners. The literature has mostly addressed two main algorithmic approaches for transport

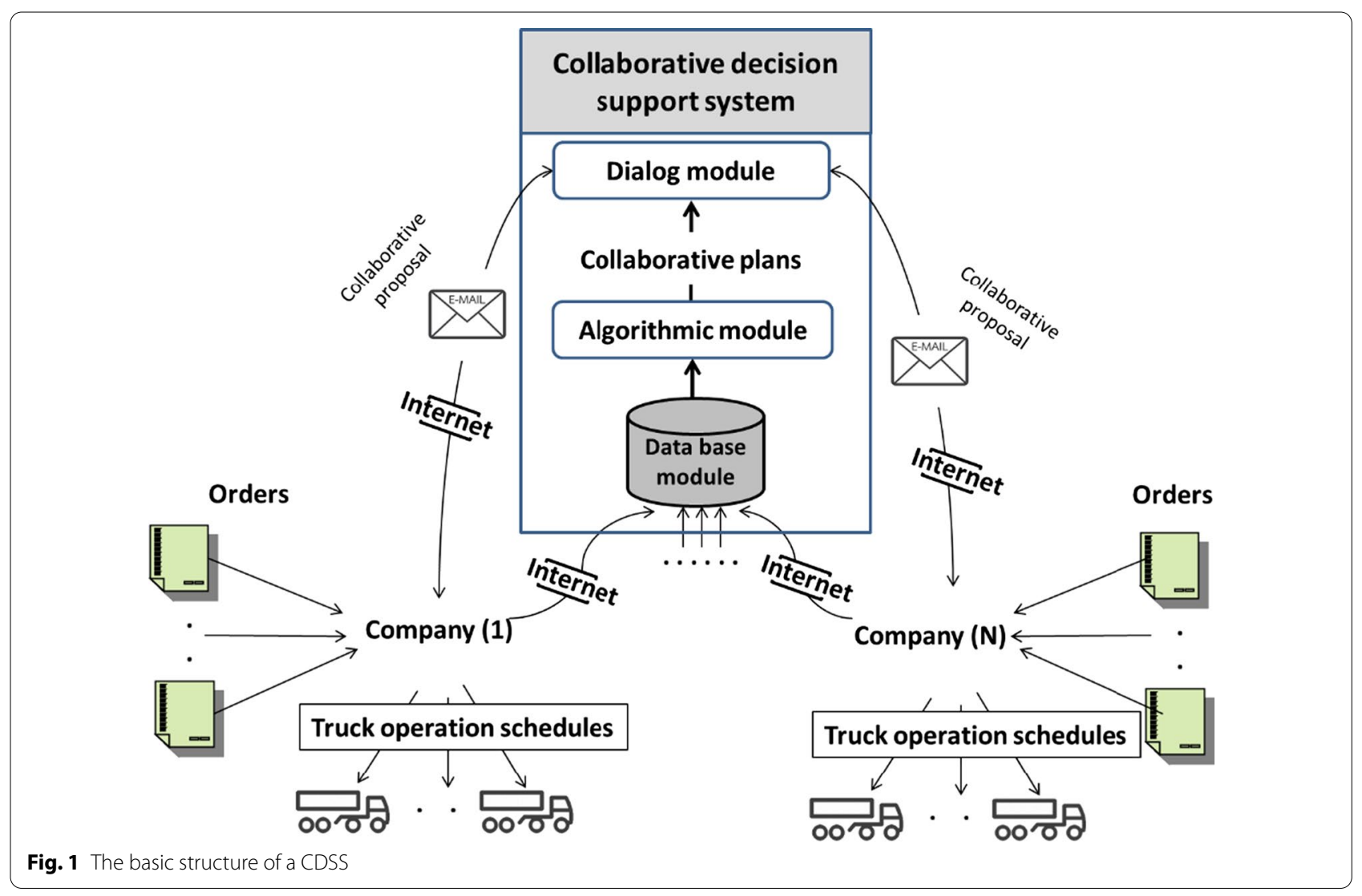


alliances: order sharing and capacity sharing. Order sharing is also known as a centralized collaborative planning approach and mostly used for collaboration among transport service providers. It requires that all partners share the information on their transport requests (orders) with a central coordinator who reallocates the orders amongst them to achieve a match between needed and available trucking capacities [28]. Compared to order sharing, capacity sharing is most frequently applied to collaboration among all types of companies. It requires that partners only share their available trucking capacities instead of sharing their transport requests [29]. Capacity sharing enables partners not to share their most sensitive information (customer requests) and therefore, companies might prefer this approach due to the high competition in the industry. E-marketplaces mostly use auction-based decentralized planning algorithms while solving twoechelon vehicle routing problems is mostly employed to manage the operations of UCCs. For various planning techniques, see $[8,20,30]$. Finally, the dialog module provides interactive communication interfaces so that partners can receive messages from the CDSS, communicate with each other, and search and filter their shared information.

\section{Search strategy and results}

Three steps have been used to identify different works reviewed in the present paper. Firstly, two databases, Web of Science (WoS) and Scopus have been searched using the following search terms:

- "Collaboration" and "Freight" with "logistics", "supply chain", or "transportation".

- "Cooperation" and "Freight" with "logistics", "supply chain", or "transportation".

The search resulted in 343 and 557 works written in English in WoS and Scopus respectively. Secondly, we carefully screened the works and included only those that satisfy the following criteria:

- Articles published in journals.

- Articles that discuss factors affecting collaborative freight transport in different supply chain contexts using qualitative and quantitative approaches.

- Articles that present case studies or results based on real applications of CTN.

Additionally, we excluded articles focusing purely on mathematical models and algorithms. The authors also made a Google search to identify relevant reports that discuss the barriers to the CTNs. We initially identified
63 works. Finally, we applied backward snowballing, i.e., examining the references of the papers identified from the second step. The backward snowballing identified 21 additional works, resulting in the inclusion of 84 works covering the period 1996 to 2020. The analyzed works included 61 journal papers, 9 review papers, 3 conference papers, 7 industry reports, 3 books, and 1 master thesis. The journal papers are published in 41 journals, e.g., Transportation Research Part E: Logistics and Transportation Review (6), European Journal of Operational Research (6), Supply Chain Management (5), International Journal of Logistics Research and Applications (4), International Transactions in Operational Research (3), International Journal of Production Research (2), Computers and Industrial Engineering (2), Expert Systems with Applications (2), and European Transport Research Review (1). The included journal papers accounted for $83 \%$ of the 84 works.

Figure 2 shows that the period 2007-2020 witnessed increasing research attention to collaboration. This might be because several collaborative logistics projects were funded by EU countries starting from 2007. To investigate the evolution of research topics over this period, the author keywords were analyzed using VOSviewer (www. vosviewer.com). Figure 3 visualizes the keywords mentioned at least two times in the identified works. Each rectangle refers to a keyword and its size is proportional to the number of publications in which the keyword was mentioned. The color gradient represents temporal trends in keyword occurrence during the period from 2007 (blue) to 2020 (yellow). From 2007 to 2010, attention was given to the role of information technologies to support collaboration in supply chain management, e.g., cryptographic technology [32], E-marketplace platforms [33], and web-based information systems [34]. In addition, studies addressed operational governance and strategic alliance contracts [15] and proposed mathematical models for collaborative planning among logistics service providers, see for example [2]. From 2010 to 2015, scholars considered trust building among partners through developing new coordination mechanisms (e.g. [35, 36],), and profit and cost-sharing methods (e.g., [37, 38]) using approaches of vehicle routing and game theory. The same period witnessed many CTN applications with CDSSs for group-decision making and negotiation among partners, e.g., $[28,39,40])$. From 2016 to 2020 , attention was given to survey papers, e.g., collaborative solutions and benefits $[12,27,41]$, collaborative vehicle routing approaches [5], cost allocation methods [9], and implementation issues [7]. Given the great advancements in Information and Communication Technologies (ICTs), more complex 


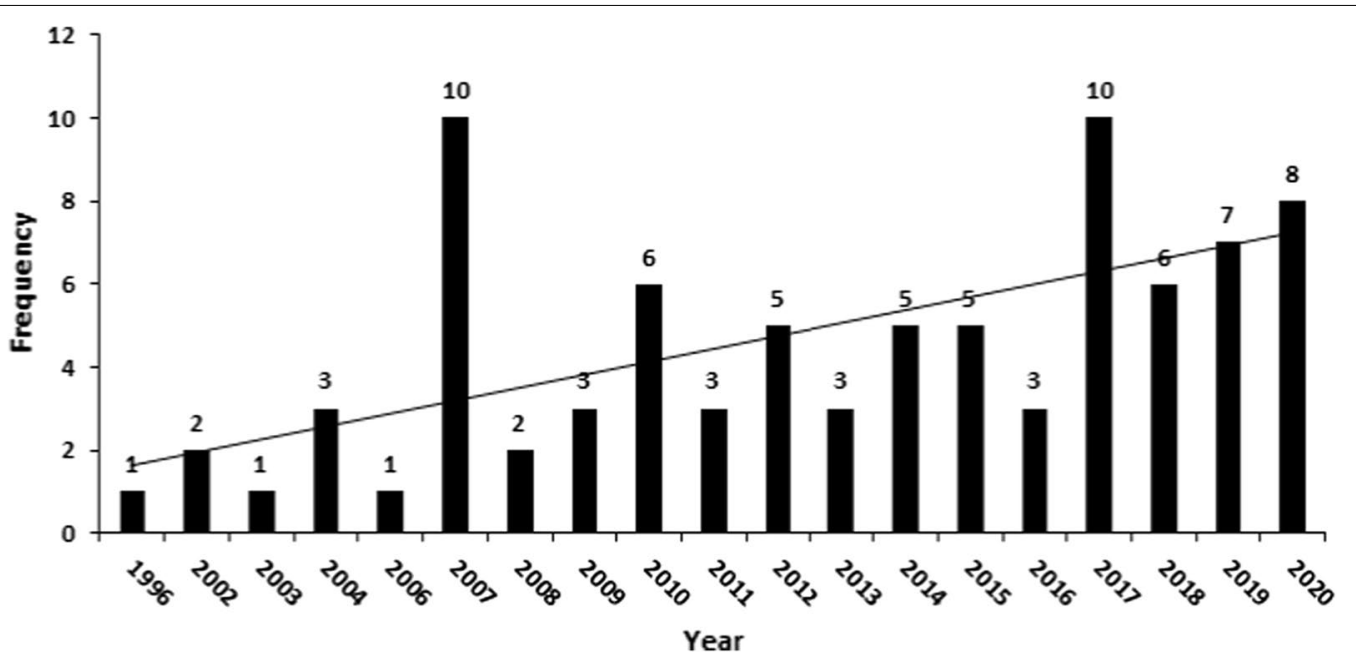

Fig. 2 The number of works per year

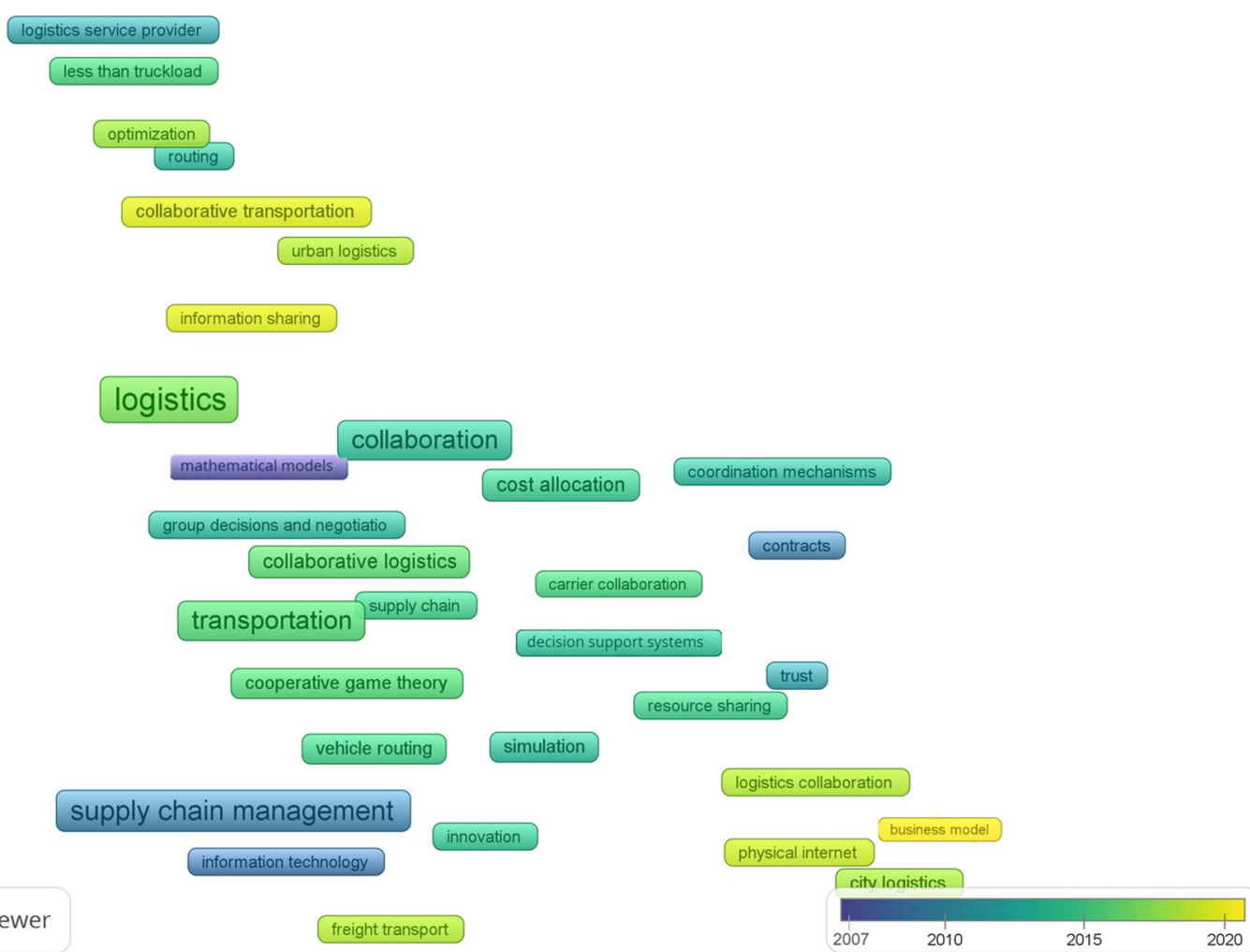

Fig. 3 Visualization of author keywords from 2007 to 2020 using VOSviewer

technologies and concepts for information sharing were studied, e.g., blockchain technology [42], and the physical internet [43]. Recently, the success factors of collaborative business models have become an important topic, especially for urban logistics $[16,17,44,45]$. This demonstrates the merits of the current work because it considers barriers related to CTN business models that have not been sufficiently considered by previous works. 


\section{The conceptual barrier framework}

To determine and categorize the barriers from the 84 works, this paper used a qualitative research approach, known as meta-synthesis, in combination with our expert knowledge. Meta-synthesis is a systematic approach for interpreting data across qualitative studies to identify qualitative evidence answering a specific research question [46]. The meta-synthesis has been successfully utilized in recent review studies to identify barriers affecting the adoption of sustainable practices, see for example [47]. The meta-synthesis includes three main steps: the first step was to perform free line-by-line coding of the different sections of each work. In the coding process, the authors summarized text that describes potential barriers. In particular, a barrier was considered an obstacle that can hinder the diffusion, implementation, and continuity of the CTN. This identified descriptive barriers capturing the meaning of the data in each work. Then subsequent works were coded into previously defined barriers, if this was not possible, a new barrier was created. The first step identified an initial set of 60 barriers from the 84 works. The second step was to group similar barriers into one broad barrier. In doing so, the authors identified the barriers that describe similar issues but were written in different wording. Then, these were grouped into one or more broad barriers. After several iterations of the second step, a final set of 31 different barriers were identified and listed with their corresponding references in "Appendix 1". The identified 31 barriers were further reviewed by an external researcher to ensure the consistency and clarity of the identified barriers. The third step was to organize the identified barriers into categories that better illustrate the nature of the identified barriers. Analysis of the existing literature revealed that most studies discussed the barriers in relation to the following categories: fundamentals of collaborative business models, quality of shared information, human factors, CDSSs, or market. To align our findings with the existing literature, the authors clustered the identified barriers into five groups: CTN business model, information sharing, human factors, CDSSs, and market. In addition, this classification also better illustrates the nature of barriers and facilitates informed decision-making since these five groups also represent the most essential elements for the CTN application. Figure 4 shows the conceptual framework for the barriers to successful implementation. As shown in Fig. 4, the identified barriers form the black box of collaboration and act as deterring factors to achieve the collaboration benefits. "Appendix 2" shows different collaboration benefits with their corresponding references. The next sections provide a deeper look into this black box by providing evidence examples for each barrier and the possible best practices to overcome each barrier. Of the 31 barriers, nine are related to the business model; five are associated with information sharing; six are related to the human factors; six are related to the CDSSs, and six are related to the market. In the following, a detailed description of the identified barriers is provided.

\subsection{Barriers related to the CTN business model}

At the early planning, the CTN's business model is formulated to describe how the CTN creates, markets, and delivers values to its customers. This business model should be seen in conjunction with existing business models of collaborating companies. A good business model can be described by answering key questions such as: what are the required resources and how they are financed, value propositions, revenue streams, cost structures, and management frameworks of the CTNs [48]. In the following, important characteristics of the business model and their inherent barriers are discussed.

\subsubsection{The organizational setup and operational governance model}

The organizational setup and operational governance model are two interrelated barriers. An organizational setup specifies how key decisions are made and the different roles and responsibilities of partners and coordinators [7]. In addition, an operational governance mode is required to ensure partners' commitment to their duties and support to CTN development $[15,49,50]$. In general, organizational setups and governance modes differ between CTNs, depending on who is the owner of the CTN. Table 1 compares the organizational setups between strategic alliances and electronic marketplaces. For example, alliance partners are often the CTN owners, and therefore, they have a strong motive and commitment for scaling up the alliance and achieving the highest efficiency. Some scholars reported that when "Who owns the CTN" is not clearly defined, this might result in a lack of commitment and support from CTN partners [44]. Electronic marketplaces have at most one purpose that is connecting different freight companies without having any direct control over how they collaborate. Therefore, organizational setup and operational governance modes are not so important in electronic marketplaces.

\subsubsection{Value propositions}

The value propositions of the CTNs describe what problems to be solved, strategies to solve these problems, and the benefits that companies can get. Although CTNs provide environmental, societal, and economic benefits (see Fig. 4), companies are more motivated to join CTNs when there are clear economic benefits, e.g., a direct measurable effect on costs $[19,51]$. For instance, 


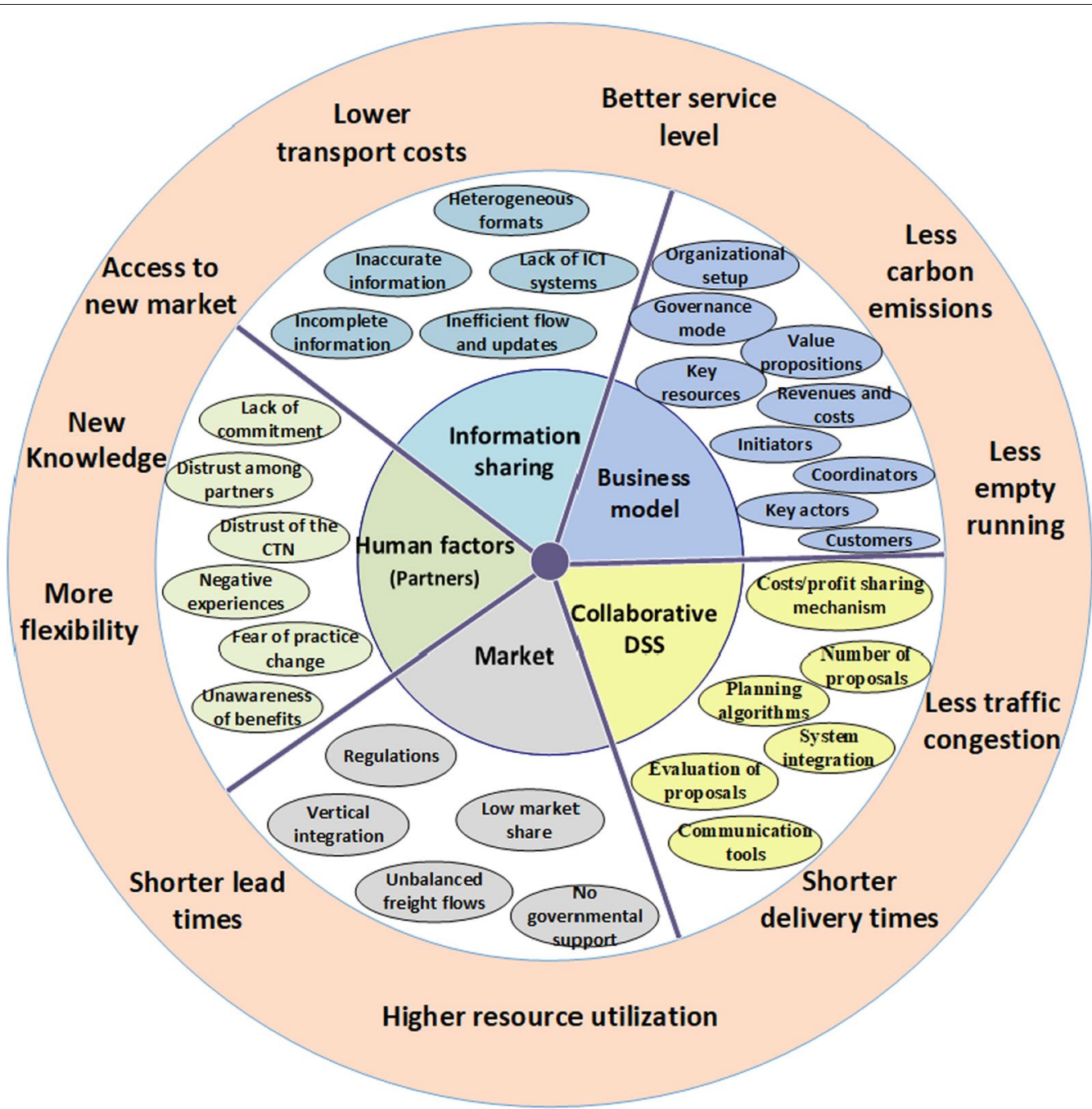

Fig. 4 Main elements of collaboration, barriers to collaboration success (black box), and potential benefits (ordered from inner to outer circles). See "Appendix 1"for references of the identified barriers and "Appendix 2" for references of potential benefits

Table 1 Comparison of organizational setups among alliances, and E-marketplace platforms

\begin{tabular}{|c|c|c|}
\hline & Transport alliances (see an example in [23]) & Electronic shipping marketplace (see an example in [21]) \\
\hline Membership & $\begin{array}{l}\text { Contract-based membership to ensure responsibilities } \\
\text { Partners might be required to pay membership fees or be share- } \\
\text { holders to enter the alliance }\end{array}$ & $\begin{array}{l}\text { Non-contract-based membership but partners have to sign the } \\
\text { electronic license agreement to use the platform and pay a fee }\end{array}$ \\
\hline $\begin{array}{l}\text { Management } \\
\text { and owner- } \\
\text { ship }\end{array}$ & $\begin{array}{l}\text { CTN management is made by a limited liability company (LLC) } \\
\text { owned by alliance partners } \\
\text { The board of the LLC includes representatives from the largest } \\
\text { partners } \\
\text { Strategic decisions might flow from above to down or might be } \\
\text { made in a horizontally centralized way } \\
\text { Partners who do not accept the decisions can leave the alliance }\end{array}$ & $\begin{array}{l}\text { The electronic marketplace is developed, managed, and owned by } \\
\text { an IT specialist company or } 3 \mathrm{PL} \\
\text { Partners (users) do not necessarily have shares in the ownership of } \\
\text { the platform }\end{array}$ \\
\hline Main duties & $\begin{array}{l}\text { The LLC is responsible for operating the CTNs, providing the } \\
\text { CDSSs, and expanding the infrastructure and transport resources } \\
\text { The CTNs are formed by the partners'assets, e.g., freight terminals } \\
\text { Partners and the LLC are responsible for sales and marketing, } \\
\text { feeding the alliance network, and executing transportation } \\
\text { services for the alliance }\end{array}$ & $\begin{array}{l}\text { The developer company develops the marketplace to connect the } \\
\text { users } \\
\text { Partners develop collaborative solutions themselves } \\
\text { The developer company operates, improves, and markets the } \\
\text { marketplace } \\
\text { The developer company verifies all necessary documents of a new } \\
\text { user before joining the marketplace }\end{array}$ \\
\hline
\end{tabular}


the CTN ' $\mathrm{CO}_{2} \mathrm{CITY}$ ' started with focusing on the environmental benefits, but eventually the focus was placed on the economic benefits to attract additional companies [16]. We note that the societal and environmental benefits are less considered by the majority of the CTNs although these sometimes are defined as one of the goals. Additionally, CTNs that offer only one service might be less attractive to many companies and might not achieve financial sustainability [44]. To improve the value proposition, CTNs should strengthen the economic benefits and offer a variety of valuable services to their partners. Examples of valuable services are transport management systems, enabling landed cost calculation, supply chain event management, routing and tendering, a spot market exchange and auctions for long-term contracts, etc. [33].

\subsubsection{Key resources}

Most studies interpret key resources as CDSSs, infrastructures, operators, and IT developers. However, logistics, supply chain, and innovation competencies are also key resources for developing, and marketing the CTN. Such competencies are not accounted for by most CTNs as indicated by [16]. Resource financing is also an important aspect. The main financing source of CTNs might come from governmental subsidies, partners, or IT specialist companies. Multiple studies showed that whenever resources are financed by partners, this ensures the commitment and support of the partners to make the CTN successful $[10,52]$. In large alliances, transport resources and assets are owned by partners while CDSSs, marketing, central management costs are financed by profits or transactional fees from the daily business in the CTN [23]. For example, the leading CTN 'Transplace' was founded in 2000 by six large freight carriers, each of which contributed $\$ 5$ million in the funding of the CTN [33].

\subsubsection{Revenue streams and cost structures}

Before CTN implementation, future revenues and expected costs should be estimated to identify conditions of break evening. Revenues are generated from payments by the partners according to the following: membership fees, per-transaction fees, profit-sharing ratio, subscription-based fees, software license fees, and Ad-based fees. These methods can be employed individually or in a combined manner [16, 23, 45]. A membership fee is paid by a partner to enter the CTN alliance. A per-transaction fee, profit-sharing ratio, or a subscription-based fee is used to derive revenues from the daily business in the CTN. The ad-based fee is paid for allowing commercial advertisements on the transport vehicles of the CTN, see for example [16], or for online advertising [33]. Service prices must be competitively set so that partners can make profits. Some studies argued that better revenue can be generated from logistics management software with subscription-based fees rather than depending solely on transaction fees or a profit-sharing ratio [33].

Two main types of costs are associated with CTNs: fixed costs and operational costs. Fixed cost includes all strategic investments and it depends on the adopted collaborative approach. For example, consolidation centers require a relatively higher fixed cost than electronic freight matching platforms [44]. Operational cost represents salaries for administrative, marketing, IT development, operating staff, and maintenance costs for any equipment to operate the CTN. As stated before, the CTN needs to increase the scope of its services to attract more companies to secure sufficient revenues for a break even.

\subsubsection{Stakeholders}

Stakeholders might include eight entities: customers (partners), coordinators, owners of the CTNs, initiators, funding agencies, public entities, consultants, and research institutions. An entity can have multiple roles, for example, the initiator can be also the coordinator and owner [16]. Selecting the right stakeholders is imperative to secure better collaboration synergies, resource financing, market-positioning, and conformity to the law. Additionally, key actors should be involved in making key decisions, problem-solving, resource financing, and not only be informed of development issues. Key actors are those stakeholders who formulate policies, finance the required resources, have the required knowledge, and perform significant freight activities [53].

4.1.5.1 Initiators Initiators must have the required skills, expertise, and market knowledge to select the best collaborative approach and the right stakeholders for this approach [53]. There are some cases where companies join the CTN but never participate in the collaboration process [45].

4.1.5.2 Coordinators In addition to the CTN management, coordinators play an important role in scaling up and marketing the CTN [23]. For instance, the Lucca municipality managed a CTN for a while, but eventually outsourced the CTN management to a logistics service provider that could offer new services and new marketing channels [16]. A pilot study reported that more than $70 \%$ of transport service providers are incentivized to join CTNs if a neutral third party, e.g., an IT development company or research institution, coordinates the collaboration processes [54]. This is because they believe that a neutral third party will treat them fairly and keep their shared information confidential $[55,56]$. 
4.1.5.3 Customers The CTN customers might be carriers, shippers, and/or receivers. The literature has mostly addressed the CTN customers through the issue of finding the right partners for collaboration [11, 41]. Identifying the right partner depend on many factors such as geographical locations of partners and their delivery areas, sizes of orders, freight flow balance, shipment compatibility [2]. Compared to other collaboration types, carrier-carrier collaboration is more problematic since it is conducted on the core business activity, i.e. transport, which is visible to their direct customers. Therefore, carrier-carrier collaboration always reports less success rate compared to other collaboration types [57]. Also, carriercarrier collaboration might have less flexibility and synergy due to transport constraints imposed by the freight owners, shippers, and receivers [7,37]. Therefore, many studies recommend that shippers/receivers join the CTNs and ask their contracted transport service providers to collaborate [37].

\subsection{Barriers related to information sharing}

A common remark from real applications is that information sharing was a significant cause for the limited success of collaboration [14]. Therefore, several studies considered it as a key requirement for the foundation of CTNs. This section discusses barriers to information sharing caused by poor IT infrastructures at the collaborating companies. This represents a significant limitation especially for small- and medium-sized companies [35, 45]. It should be noted that information sharing might also be constrained by the attitudes of individuals. This will be discussed in the 'human factor' category of barriers. Five barriers are identified related to information sharing.

\subsubsection{Incomplete logistics information}

Optimal collaborative decision making requires detailed logistics information such as volume, pickup and delivery times, locations, and specifications of the needed trucks. Most collaborative planning approaches are mostly based on the assumption that the required information is always available. However, in practice, such information is rarely documented and is often estimated based on the planners' experience [58]. This issue has been also reported by many studies on supply chain and logistics collaboration $[59,60]$. The issue can be alleviated by minimizing the input data required for the collaborative planning approach. For example, the matching algorithm of the CTN 'Tri-visor' utilizes only the geographical data, i.e. origin and destinations, of transport requests to match the most frequently used routes by companies [61].

\subsubsection{Inefficient information flow and updates}

Partners might not share their logistics information simultaneously and/or do not timely update their shared information [12, 62]. Amours and Rönnqvist [63] stated that inefficient information flow is a big challenge to achieving connectivity among partners. Real-time information flows from partners were an essential requirement for the CTN implementation in [28]. This barrier might frequently happen if companies use simple database software and thus, it might be difficult for them to timely update the CDSS with any changes in their shared information. This might result in invalid and/or lowquality collaborative planning decisions.

\subsubsection{Inaccurate information}

Inaccurate information can result in completely different collaborative decisions and higher or lower estimation of the collaboration profits [39]. Several studies showed that a low level of digitalization at some partners leads to highly inaccurate information $[12,63,64]$.

\subsubsection{Heterogeneous information formats}

Some partners may measure the size of the order in different units, e.g., loading meter or cube meter. In this case, the CDSS requires an additional processing effort to unify the information formats. This in turn can lower the quality of the decision-making process [12]. In addition, the formats of the data files shared by partners may also vary when partners have different transport systems [34, 65]. According to Liu et al. [66], the similarities among partners in information technologies have to be considered when selecting partners for CTNs.

\subsubsection{Lack of ICT systems}

Efficient collaboration requires that partners manage their operations using advanced ICT systems such as transport and warehouse management systems, barcode systems, and fleet telematics systems [67]. In the CDSSs developed by [28], partners were required to use advanced ICT systems for sharing reliable, complete, and real-time information, and quickly evaluate collaborating opportunities. Furthermore, such partners can provide better visibility as well as service level by allowing partners to track the shipments [68]. For example, a partner without advanced ICT systems cannot inform other partners of the real-time location of the delivery trucks or estimate expected delivery time to customers. Amours and Rönnqvist [63] noted that the lack of software agents, standardized information flows, and electronic data exchange technology represent a challenging problem related to collaborative planning and might leads to errors in shared information and collaborative planning. 


\subsection{Barriers related to human factors}

Cruijssen [69] noted that the attitudes of transport planners might hinder the collaboration's success. Basso et al. [12] stated that problems arising from human factors are distrust and opportunism. Such behavioral problems make it difficult for companies to collaborate even if positive business cases exist $[68,69]$. In the following, we illustrate seven barriers related to human factors.

\subsubsection{Experiences}

Some transport planners might have negative experiences from past collaboration attempts. For instance, a partner may share many orders but gain small profits, while other companies share relatively few orders and get more profits. Some partners might provide false information intentionally on capacities and prices to get more matches and gain sensitive information on competitors, compared to the partners whose delivery costs are relatively higher. This may lead to instability and dissolution of collaboration [70]. Some CDSSs detect intentionalfalsification behaviors through feedback rating, then partners who misbehave are blacklisted, see for example TIMOCOM. A real application in Germany showed that the fees offered in the CTN are always higher than the fees outside the CTN [28]. In addition, some companies perceive that collaborative practice may lead to a reduction in their autonomy in the future [35].

\subsubsection{Lack of commitment}

Kwon et al. [52] defined commitment as the belief of the partners that their partnership is so important and so, they do maximum efforts for maintaining it. Lydeka and Adomavičius [70] noted 'a common theme among responders [carriers] was dissatisfaction with some members of cooperation which failed to follow through with commitments.' The success of collaboration requires that partners commit to providing the expected service level and paying promised savings. When partners do not fulfil their commitments, this certainly lowers the CTN's competitive advantage [71]. When this occurs frequently, companies prefer partners from their networks using phones to ensure quick responses and reliable services. With an increasing in the frequency of late responses or no commitments, CTNs lose their competitive advantage, i.e. short lead time and the ability to serve urgent requests at low cost.

\subsubsection{Distrust among partners}

Distrust among partners is cited as the most challenging barrier to successful collaboration and it leads to further issues such as fear of sharing information [50, 70, 72, 73]. The lack of trust becomes worse in carrier-carrier collaboration since partners collaborate on their core business activities [74]. The literature provides some suggestions for improving trust. Badraoui et al. [10] suggest that partners invest in the CTNs since they will do their best to achieve a good return on their investments. Lydeka and Adomavičius [70] suggest that partners start with collaboration on non-core business activities, e.g., purchasing fuel and tires in large quantities, before collaborating on their core business activities. Los et al. [75] suggest that trust can be improved by adopting collaborative approaches requiring less information sharing. The use of cryptographic and blockchain technologies was investigated as a solution for securing information sharing among partners, and thus trust is improved [32, 42]. The CDSS can allow its users to advertise their freight either privately or publicly [76].

\subsubsection{Distrust of the CTN}

This barrier means that partners distrust both coordinators and methodologies of the CDSS [12, 55, 56]. Many CTNs were disintegrated because of such issues [31]. Trust among the coordinator and the partners necessitates the existence of positive past collaboration experiences [77]. Vargas et al. [45] argued that this issue might happen because small carriers often lack IT-based skills and so, it is not easy for them to understand how and with whom their shared information will be used in the CDSS. Another reason for this barrier is that compared to a traditional freight broker, some CTNs do not take any responsibility for the actual service provided to the partners [76]. Besides, transport operation managers often believe that their way of finding partners is the best and any technology or system developed to replace their ways of working is not practical [70].

\subsubsection{Fears of changing their business model}

Companies may worry about the future consequences of changing their business models towards collaborative practice and joining transport alliances [78]. According to Lydeka and Adomavičius [70], the managers in the small companies are most often the founders and they consider their companies as "their baby" and so, it is no easy for them to lose direct control over their customers. Furthermore, collaboration may reduce the dissimilarity between their transport services and simultaneously increases the distinctiveness between their services and the non-collaborator 's service [79]. Consequently, small companies may be afraid that collaboration can cause them to lose customers or get pushed out of the market completely.

\subsubsection{Unawareness of collaboration benefits}

Pilot studies assured that increasing the partners' awareness of the collaboration benefits is imperative before 
real applications $[69,78]$. Many CTNs were launched in Europe, but they were marketed to the freight industries with too much focus on sustainability goals, i.e. reduced congestion and emissions. This in turn ignores the important fact that companies prioritize what can improve their profits over societal or environmental benefits [80]. Transport managers in small companies might have less formal education, thus they do not care about sustainability issues and do not believe in the benefits of collaboration [70]. Other reasons may be the misconception of collaboration aims and mechanisms, lack of experience, and poor understanding of how sustainable performance can be used as a competitive advantage.

\subsection{Barriers related to CDSSs}

CDSSs aim basically to connect the different freight firms and enable them to share their information. Additionally, CDSSs might include algorithmic approaches for making decisions on joint route planning, freight auctions, tendering, and profit allocations [5]. Some CDSSs might integrate real-time logistics information into the decision-making process if partners have the required technology to supply their real-time information[28]. Many scholars have developed complex algorithms utilizing several variants of the vehicle routing problem [8], while the industrial communities focus on enabling technologies for real-time information, developing effective userinterface and predictive analytics. In the following, six barriers related to the CDSSs are discussed.

\subsubsection{Cost/profit-sharing mechanism}

Sharing profits and costs in a way that is accepted by all partners is a significant barrier to the collaboration [9]. For instance, eight forest transport companies discontinued the collaboration since the outcomes were insufficient [81]. Although review studies [5, 9] identified more than 40 profit-sharing mechanisms, many studies agree that real applications require a transparent, straightforward mechanism rather than a sophisticated, theoretical one [82, 83]. The mechanism should consider partners' characteristics, e.g., sizes of partners and their contributions to the collaboration synergies. For instance, companies that have large market coverages can significantly improve collaboration synergies. Such companies have to be privileged when sharing the collaboration profits [82, 84]. Mathematical approaches might not get the consensus of all partners and they might show inconsistent performances from a case to another [82]. To overcome this issue, some CTNs adopt a negotiation-based policy in which profit sharing is negotiated among partners instead of using a specific method imposed by the CTN [85]. In this way, partners are not required to share their most sensitive information, i.e. service costs, with the coordinators. It also allows them to estimate the cost by their own accounting systems [86]. One issue with negotiation is that large partners might use their market position to take advantage of small partners. One way to overcome this issue is to specify a set of sharing policies instead of only one policy, then partners can negotiate on which rule they use [82].

\subsubsection{Plenty of collaborative proposals}

An important barrier is the too many 'collaborative proposals' emails that transport planners receive daily from the CDSS [28]. This consumes the planners' time in reviewing these emails and as the day goes on, more emails are piled up [87]. Some studies suggest imposing filtering constraints on the delivery time window, required handling equipment, truck class, or a specialized driver [88]. Such filter constraints might not be possible if the shared logistics information lacks the required details. Some studies handled this issue through predictive analytical tools that process previously accepted proposals to extract the human preference regarding proposals of interest [39]. Trucker Tools, a smart logistics solution provider, predicts the proposals of interest by an email read-and-analysis method that is based on techniques of machine learning and natural language processing [87]. Some studies solve these issues using knowledge-based DSSs integrated with multi-criteria decision-making approaches [58].

\subsubsection{Collaborative planning algorithms}

Typically, CTNs have huge amounts of information flows from many trucks serving hundreds of transport requests across several postal codes and each transport request may have different transport requirements. Thus, the efficiency of collaborative planning algorithms is a key requirement for efficient real-time planning decisions $[8,40]$. This becomes more crucial for transport requests characterized by short lead times such as express couriers $[28,62]$. In addition, the design of the planning algorithm might be constrained by information availability. Most real applications developed algorithms are based on the rolling horizon concept $[28,40]$. The idea of the rolling horizon is to run the algorithm and keep the identified plans in an adaptive memory. Every time, an event occurs, e.g., a new request is known or a truck has finished its current job, the algorithm is rerun considering the latest updates in shared information.

\subsubsection{Evaluation of collaborating proposals}

A recent survey [5] showed that most studies evaluate and rank proposals based on the economic impacts (e.g., total travel distance) while environmental and societal impacts (e.g., emissions, safety, and service level) are paid 
relatively less attention [4]. This certainly underestimates the collaboration benefits. In addition, past services' quality provided by the partners is not considered when evaluating new proposals. Some CTNs measure the service quality by the ratings of the partners for on-time performance, ratios of damages, and claims [89]. Accordingly, partners who have low rating scores will rarely acquire collaborating proposals. This way can operationalize the negative implications of the partners not fulfilling their commitment.

\subsubsection{Lack of interactive communication tools}

Email server clients and websites are the most frequently used communication tools in existing literature [28, 34, 90]. With increasing dynamics, competition, and uncertainty in the logistics industry, these traditional tools are unsatisfactory and can impair the efficiency of collaborators. Some CDSSs use advanced web-based mobile applications and custom APIs to facilitate tracking and check-ins. For example, TIMOCOM [22] embedded a messenger service into its freight exchange platform for chatting among collaborating partners. Compared to emails, messengers save time and are much easier to be used, especially when negotiating with many partners at the same time.

\subsubsection{Lack of system integration}

System integration allows for automatic information flows from partners' planning systems to the CDSS and back [57]. Many studies cited the lack of system integration as a significant barrier to collaboration success. Lieb and Miller [91] stated that coordination by 3PLs failed due to the inability to integrate information systems of buyer and provider. Piplani et al. [92] noted that for 3PLs "it would become imperative that they integrate [their information systems] with the IT-systems of their partners and customers to increase the effectiveness of the systems and to get the real value out of them". For achieving system integration, companies have to upgrade their information systems to an agent-based information system to enable connectivity with the information systems of their partners, customers, and suppliers [63]. However, this requires companies to invest in their IT- infrastructure, which is not an easy decision for them to make.

\subsection{Barriers related to the market}

The market represents the physical place, i.e. a country or set of countries, where collaborative activities are to be performed. The market characteristics are a key determinant for probability, potentials, strategies, and legality of the collaborative practices [70]. Market characteristics include important factors such as regulations on collaborative practices, intensity of vertical integration among different freight players, and freight flow balances among regions. In the following, we illustrate five barriers associated with the market characteristics.

\subsubsection{Regulations}

Most market imposes regulations (e.g., competition laws) on the collaboration among companies and such regulations might act as legal barriers to horizontal collaboration. For example, the European Union Antitrust Act [93] states that agreements and business practices that restrict competition are generally not allowed. This disables information sharing among competing companies because this might lead to collusion if partners agree on a specific service price or lead to market protection if partners reject that other companies join the CTN. Such regulations are more concerned with collaboration among big companies. Therefore, many CTNs are allowed for small and medium-sized companies if they do not coordinate prices or capacity. In other words, forming a CTN is allowed when a trustee party leads the collaboration and makes sure that the collaboration satisfies the competition laws and the shared information remains strictly confidential $[38,69]$.

\subsubsection{Vertical integration}

For better customer privacy and service quality, shippers or freight receivers outsource their freight transport via long-term contracts to freight carriers. Such a long-term contract is known as vertical integration [36]. Vertical integrations also provide carriers with stable demands. However, the contractual agreements might disallow carriers to collaborate if shippers impose specific delivery times or prefer deliveries with their contracted carriers' private fleet [36]. With high vertical integration, a few transport requests are shared in the market and this, in turn, reduces the revenues for the CTNs. Therefore, multiple scholars suggest that shippers/receivers can be rewarded relatively lower service prices for making their delivery characteristics flexible, e.g., allowing delaying or advancing the pickup or delivery times [7, 37].

\subsubsection{Imbalanced freight flows}

On the national level, there might be imbalances in the freight flows among different regions. This imbalance varies according to the freight types. This causes most trucks to drive fully loaded from some regions and return partially or fully empty in the reverse direction $[45,94]$. In this case, national carriers might have lower collaboration synergies, and finding a partner for collaboration is a significant barrier. To overcome this issue, Lydeka and Adomavičius [70] suggest inviting international 
carriers to the CTN. In case of imbalanced freight flow, the CDSSs must detect back-hauling opportunities among partners not only "collect-and-or-drop" opportunities [61].

\subsubsection{Low market share of the CTN}

In recent years, IT development companies like Uber Freight and TIMOCOM launched mobile- or web-based marketplaces that offer many logistics solutions including freight matching services. Many companies have explored the values of such marketplaces and started to extensively use them in their daily operations [95]. Therefore, unless a new CTN brings new and useful values than the available marketplaces, it might not attract the freight firms and gain a sufficient market share to generate economies of scope [96]. The recent advances in electronic marketplaces might be one of the main reasons why some research projects and startups on collaborative freight transport are no longer operational after their pilot development [20,21]. Therefore, the CTN initiators have to first analyze the transport market before starting a new CTN.

\subsubsection{No public incentives for collaborative practices}

Public authorities can fund collaboration initiatives and start-ups that require a relatively high investment to develop CDSSs [45]. For example, Project U-TURN by the European Commission was proposed to encourage collaboration in city logistics to reduce carbon emissions and transport costs. Project NextTrust aimed to develop a collaborative decision-making system for identifying collaboration potentials through matching excess capacities with available loads. See more initiatives funded by public subsidies in [97]. In addition to funding, policies like granting priority access to highly utilized vehicles or vehicles serving consolidation centers can encourage the collaborative practice $[78,94]$.

\section{Insights into the identified barriers and solution strategies}

\subsection{Insights into the identified barriers}

To provide some insights into the findings, Table 2 shows a two-dimensional matrix based on types of barriers and the CTN solutions. Each cell indicates the number of works that reported a specific barrier for a particular CTN solution. To visualize the results, we use a color map where high values are marked in green, low values are marked by yellow-green, and zero value is marked in red. It should be noted that some works reported more than one barrier and therefore, the sum of all numbers in Table 2 does not equal 84 . Thirty-three works reported business model-related barriers (strategic alliance 48\%, UCCs $24 \%$, electronic marketplace platforms $6 \%$, and general works 21\%). Few contributions addressed electronic marketplace platforms because they do not have any direct control over how users collaborate and therefore most aspects of business models are not so relevant, while business model-related barriers are considered important to both strategic alliances and UCCs. In particular, value propositions, revenue streams, and cost structure are important barriers to UCCs while almost all barriers related to business model were considered important to strategic alliances. Twenty works reported barriers of information sharing and are classified into a strategic alliance $(70 \%)$, UCCs $(0 \%)$, electronic marketplace platforms $(5 \%)$, and general works (25\%). Most information related-barriers are important to strategic alliances. The literature rarely addressed informationrelated barriers when implementing the UCCs and electronic marketplaces. However, many general works confirmed that the information-related barriers are significant issues with implementing supply chain and logistics collaboration $[12,59,63]$. Thirty works reported barriers due to human factors and are disturbed into a strategic alliance (63\%), UCCs (10\%), electronic marketplace platforms (11\%), and general works (14\%). Most barriers were reported by studies on strategic alliances. Trust-related issues were mostly reported by studies on alliances and electronic marketplace platforms. Overall, distrust among partners, distrust of the CTN, fear of changing business model, and unawareness of collaboration benefits are common and important barriers in almost all collaborative solutions. Thirty-one works reported barriers of CDSSs and are classified into a strategic alliance $(61 \%)$, UCCs $(6 \%)$, electronic marketplace platforms (6\%), and general works (16\%). Generally, the cost/profit-sharing mechanisms and lack of interactive communication tools were most frequently cited as an important barrier to strategic alliances. The plenty of collaborative proposals is an important barrier to electronic marketplace platforms since they often have many companies resulting in too many collaborative proposals. Twenty works reported market-related barriers and are distributed into a strategic alliance (50\%), UCCs (15\%), electronic marketplace platforms (10\%), and general works (25\%). All market barriers were reported by studies on strategic alliances and imbalanced freight flows were the most cited barrier while studies on electronic marketplace platforms reported only one market barrier, i.e. low market share of the CTN.

\subsection{Solution strategies}

The following strategies can be considered to overcome the business model-related barriers. All stakeholders should agree on aims, operating rules, and the most suitable collaborative solutions that achieve clear and sensible 
Table 2 Classification of identified barriers and the CTN solutions

\begin{tabular}{|c|c|c|c|c|c|}
\hline $\begin{array}{l}\text { Barrier } \\
\text { category }\end{array}$ & Specific barriers & $\begin{array}{l}\text { Strategic } \\
\text { Alliances }\end{array}$ & UCCs & $\begin{array}{l}\text { Electronic } \\
\text { marketplace } \\
\text { platform }\end{array}$ & $\begin{array}{l}\text { General } \\
\text { works* }\end{array}$ \\
\hline \multirow{8}{*}{$\begin{array}{l}\text { CTN business } \\
\text { model }\end{array}$} & Organizational setup & 1 & 0 & 0 & 2 \\
\hline & Operational governance mode & 3 & 0 & 0 & 0 \\
\hline & Value propositions & 0 & 3 & 1 & 1 \\
\hline & Key resources & 2 & 1 & 0 & 1 \\
\hline & Revenue streams and cost structures & 2 & 2 & 1 & 0 \\
\hline & Initiators & 1 & 1 & 0 & 0 \\
\hline & Coordinators & 4 & 1 & 0 & 0 \\
\hline & Customers & 3 & 0 & 0 & 3 \\
\hline Total & & 16 & 8 & 2 & 7 \\
\hline \multirow{5}{*}{$\begin{array}{c}\text { Information } \\
\text { sharing }\end{array}$} & Incomplete logistics information & 3 & 0 & 0 & 1 \\
\hline & Inefficient information flow and updates & 3 & 0 & 0 & 1 \\
\hline & Inaccurate information & 3 & 0 & 0 & 1 \\
\hline & Heterogeneous information formats & 3 & 0 & 0 & 1 \\
\hline & Lack of ICT systems & 2 & 0 & 1 & 1 \\
\hline Total & & 14 & 0 & 1 & 5 \\
\hline \multirow{6}{*}{ Human factors } & Experiences & 3 & 0 & 0 & 0 \\
\hline & Lack of commitment & 2 & 0 & 0 & 1 \\
\hline & Distrust among partners & 4 & 1 & 3 & 2 \\
\hline & Distrust of the CTN & 6 & 0 & 0 & 1 \\
\hline & Fears of changing their business model & 2 & 1 & 0 & 0 \\
\hline & Unawareness of collaboration benefits & 2 & 1 & 0 & 1 \\
\hline Total & & 19 & 3 & 3 & 5 \\
\hline \multirow{6}{*}{ CDSSs } & Cost/profit-sharing mechanism & 6 & 0 & 0 & 2 \\
\hline & Plenty of collaborative proposals & 3 & 0 & 2 & 0 \\
\hline & Collaborative planning algorithms & 2 & 1 & 1 & 1 \\
\hline & Evaluation of collaborating proposals & 2 & 0 & 1 & 1 \\
\hline & Lack of interactive communication tools & 4 & 0 & 1 & 0 \\
\hline & Lack of system integration & 2 & 1 & 0 & 1 \\
\hline Total & & 19 & 2 & 5 & 5 \\
\hline \multirow{5}{*}{ Market } & Regulations & 2 & 0 & 0 & 2 \\
\hline & Vertical integration & 2 & 1 & 0 & 0 \\
\hline & Imbalanced freight flows & 3 & 0 & 0 & 1 \\
\hline & Low market share of the CTN & 1 & 1 & 2 & 1 \\
\hline & No public incentives for collaboration & 2 & 1 & 0 & 1 \\
\hline Total & & 10 & 3 & 2 & 5 \\
\hline
\end{tabular}

*Works reporting barriers to collaboration in generic terms without addressing specific CTN solutions

benefits for them $[19,51]$. The CTNs have to be managed by a strong LSP with high practical and technological experiences [23]. To attract more companies, the CTN should offer a variety of valuable services such as transport management systems [33]. Additionally, shippers and retailers might be involved in the CTN to bring their contracted carriers or LSPs to the CTNs [7, 37]. Also, the CTNs should have a clear cost structure ("Who pays what") for all stakeholders and benefits have to be allocated according to the contribution of each stakeholder to the cost structure [78]. Furthermore, operational governance models have to be in place to secure the commitment of all stakeholders to their responsibilities $[7,15$, $49,50]$. Regarding the information sharing-related barriers, a primary and necessary step is to check carefully the digitalization readiness of the partners. This helps to select the most suitable information exchange systems that might be based on real-time logistics information as in [28] or historical logistics information as in [61]. Information quality has to be defined clearly and considered 
when selecting the CTN partners [59]. Partners are recommended to standardize their information flows, e.g., using electronic data exchange technology, to enable rapid information flows with high accuracy [63]. Regarding human factor-related barriers, trust can be improved by adopting group decision-making processes involving all stakeholders when identifying the CTN characteristics $[19,98]$. In addition, trust uncertainties about the benefit/ cost-sharing allocation and shared information privacy can be eliminated by open and frequent communications among all stakeholders [59]. There is a need for using advanced information technologies (e.g., advanced webbased mobile applications and blockchain technologies) to ensure high information security, and thus trust can be improved [32]. To eliminate the negative perception of collaborative practices, awareness of the CTN benefits should be spread at the industry level $[69,70]$. Regarding CDSSs-related barriers, negotiation-based policies might be adopted for allocating costs and profits so partners can negotiate and select among different sharing policies instead of using a specific method imposed by the CTN [82, 85]. Partners should transit towards an agent-based information system that enables connecting the entire CTN and allows for reactive, transparent, integrated, and reliable collaborative planning [63]. Machine learning techniques are valuable to predict the preference of partners and impute any missing information [87]. Regarding market-related barriers, legal barriers (e.g., competition law) can be overcome by involving a trustee party $[38,69$, 99]. Authorities might relax regulations that restrict the collaboration practice and might impose taxes on carbon emissions from freight vehicles, specific load factors, and road pricing schemes $[100,101]$. To resolve the imbalanced freight flow among the country's regions, international partners might join the CTNs [70] and possible back-hauling opportunities among partners are detected [61].

\section{A stage-gate model of the decision-making process in CTN implementation}

The conceptual barrier framework indicates that several barriers should be analyzed before the implementation of the CTN. Thus, there is a need for a decision-making model to guide the CTN implementation process with consideration to the identified barriers. As mentioned by Martin et al. [102], most existing decision-making models have a broad scope towards strategic alliance formation in general, while very few contributions addressed models for implementing and managing horizontal collaboration. For example, Fawcett et al. [103] presented a three-stage model to develop supply chain collaboration. Their model starts from creating commitment and understanding and removing resisting forces to collaborative practice, and continuously improving collaboration capabilities. Also, Bhattacharjee and Mohanty [104] developed a conceptual model that includes nine stages: environmental scan, internal alignment process, partner selection, alliance alignment, project alignment, work process alignment, review and feedback, and reward and recognition. Regarding horizontal logistics collaboration, Verstrepen et al. [55] presented a four-stage model: strategic positioning, design, implementation, and moderation. However, their model did not adequately consider important aspects such as partner selection and interactions among different implementation stages. More recently, Martin et al. [102] presented a decision model for developing horizontal logistics alliances consisting of five stages: orientation, partner selection, negotiation, implementation, and management. Despite the merits of existing models, most of them hardly discussed potential barriers that need to be considered in each stage. Thus, we propose a stage-gate model to consider the different barriers into a guideline of the CTN implementation decision-making process. The proposed model builds over existing models and addresses their limitations, e.g., the fact that existing models did not include potential barriers in each stage. The stage-gate model is a project management methodology used to guide the project creation from an idea-to-launch systematically and efficiently. The model decomposes the overall decision-making process into a number of sequential stages and gates $[105,106]$. Stages represent the different phases of the project where analytical studies and/or CDSSs are developed. Each stage has a gate at which the decision makers give a decision on whether to proceed to the next planning stage. Moreover, the stage-gate model has an easy-to-understand structure and thus, the proposed model provides a valuable tool to guide the CTN implementation process with considerations to the identified barriers.

Figure 5 shows the proposed model that divides the CTN implementation decision-making process into four stages involving scoping, building the business case, developing the CDSS, and operating and maintaining the CTN. These stages are relevant to the CTN implementation as suggested by previous studies [51, $55,102]$. However, it is worth noting that the stagegate model conceptualizes that not all the four stages might be needed in the CTN implementation decisionmaking process. Based on the need of the stakeholders, one or more stages might be enough for the CTN implementation decision-making process. For example, initiators and partners might be only interested in identifying a suitable CTN solution based on their objectives. In this case, the scoping stage alone can be enough to provide this information by evaluating the 


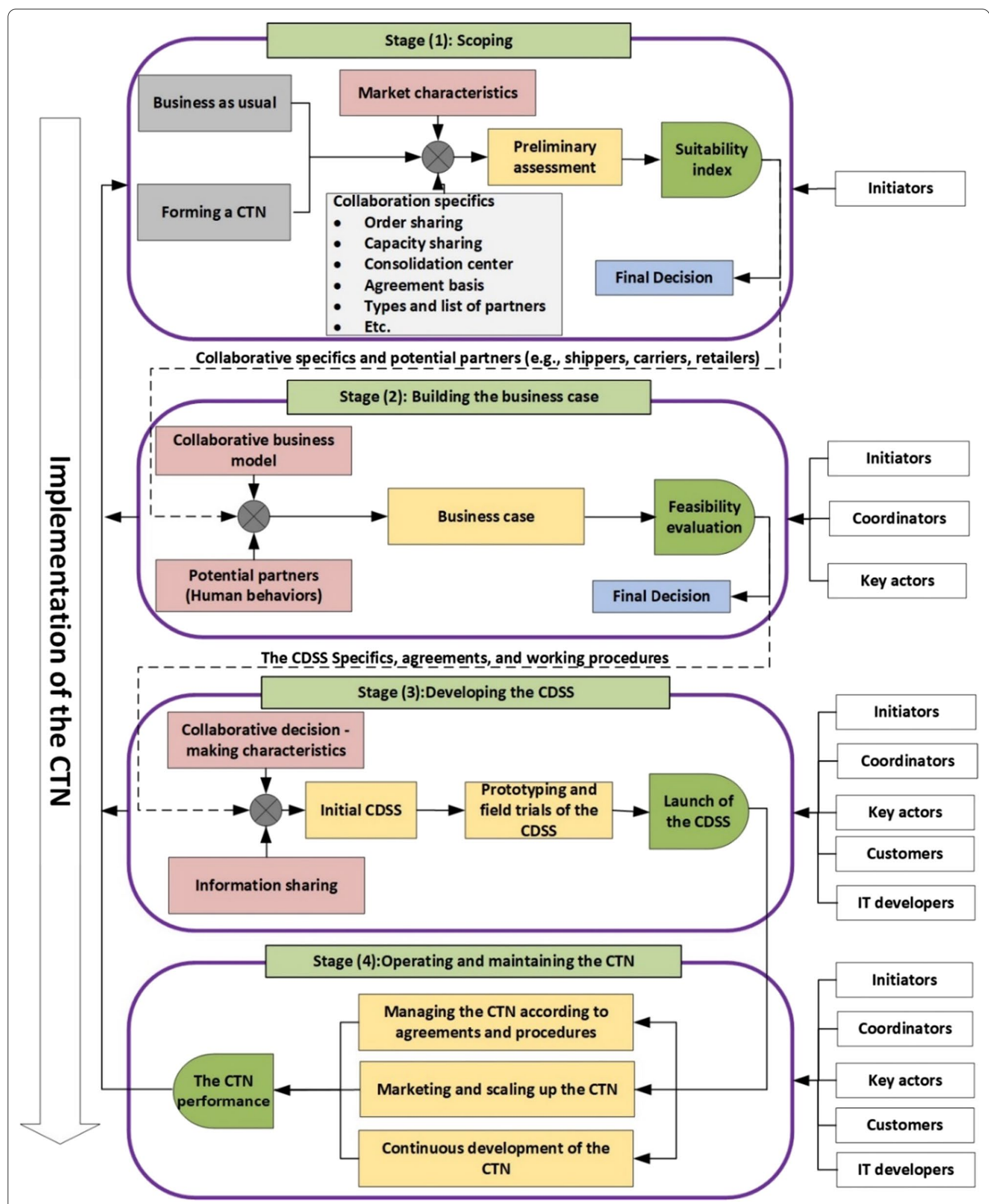

Fig. 5 A stage-gate model for the CTN implementation decision-making process 
characteristics of the proposed CTN solution against the market barriers. At each stage, knowledge on the relevant barriers can provide the right base for making the proper decisions at its gate. For example, suppose that an initiator, e.g., shippers or 3PL, wants to initiate a CTN and aims to identify the suitable specifics of the CTNs and an initial list of partners. The scoping stage can be used to achieve this aim. Within the scoping stage, the initiator has to evaluate the specifics of possible collaborative approaches against the market barriers using approaches like the SWOT method. The scoping stage constitutes a preliminary assessment of whether the CTN is better than as-usual-business practice and which collaborative approach is most suitable for the potential partners.

If forming a CTN is found better than the current practice of the partners, the initiator proceeds to the next stage where the right partners are selected, followed by inviting other key stakeholders to develop a viable business case for the CTN. At 'the building business case' stage, relevant stakeholders require knowledge on barriers associated with both the CTN business model and human factors to develop reliable fundamentals of the collaborative business model leading to a sound business case. This might require information on operational costs, fixed costs, expected demand, and the use of simulation to investigate the feasibility of the suggested business case. Besides, it is also critical that the selected partners have a clear understanding of the CTN objectives, and that they agree on the basic rules, e.g., organizational setup and resource financing, that support viability of the developed business case.

If a positive business case could be developed, the next stage is to develop the CDSS according to the specifics of the approved business case. At 'the developing CDSS' stage, the first step is to analyze the digitalization level of the partners and investigate their logistics information quality. It should be noted that developing a CDSS which demands detailed information might face severe data-quality issues and limit the success as well as scaling-up of the CTNs [61, 122]. Similar to previous steps, knowledge on the barriers relevant to this stage will help to develop the right CDSS that satisfies the partners' needs and their data-quality conditions.

The final stage concerns the operation, maintenance, and evaluation of the CTN. At this stage, great attention should be paid to marketing and scaling up the CTN. Besides, the CTN performance must be evaluated primarily on economic performance, e.g., cost savings of the partners. It is also essential to evaluate aspects like commitment and trust of partners, shared information flows, and partner satisfaction. Based on the CTN evaluation results, decision makers must decide on some actions to avoid the CTN failure, for example changing or adding new rules to the business model and improve subsequent elements in other stages. All or some of the four stages might be repeated periodically for the CTN development process or when a new partner is willing to join the CTN.

\section{Conclusions, limitations, and future research directions}

Despite the extensively reported benefits and the government funds to encourage the uptake of CTNs in the horizontal setting, their real applications have been rare and with varying degrees of success. Thus, this paper contributes to existing literature through an extensive review of the barriers, developing a conceptual barrier framework, and proposing a decision-making model for the CTN implementation process. 84 studies on horizontal collaborative logistics have been analysed and in total, 31 barriers are identified. To illustrate the barrier nature and facilitate informed decision-making, these barriers were conceptualized into a framework of five categories involving the business model, information sharing, human factors, the CDSSs, and the market. Of the 31 barriers, nine are related to the business model; five are associated with information sharing; six are related to the human factors; six are aligned with the CDSSs, and six are related to the market. The main finding is that the successful CTN implementation is not only dependent on developing a CDSS for sharing information and making collaborative decisions, but it is strongly driven by the ability to identify and overcome the barriers associated with the collaborative business models, human factor, market, and shared information. These barriers form the black box of the CTN implementation process and negatively affect the collaboration benefits. Thus, the current work provided a deep look into this black box and identified a wide range of barriers by illustrating evidence examples and the best practices for each barrier in the literature. Moreover, the results showed that implementing strategic alliances face much more barriers compared to UCCs and electronic marketplace platforms. This is because the more the collaboration becomes strategic, the more resources and sensitive information sharing are needed. Business model-related barriers were often reported by studies on UCCs and strategic alliances while the literature rarely discussed business models of the electronic marketplace platforms. Information barriers were exclusively reported by studies on strategic alliances where the need for sharing detailed and high-quality information is higher than other CTN solutions. Trust-related barriers were mostly reported by studies on different CTN solutions. CDSSs related-barriers were mostly considered by studies on strategic alliances and electronic marketplace 
platforms while studies on UCCs addressed the CDSS through only the need for solving complex two-echelon distribution problems and system integration. Market barriers were most reported by studies on strategic alliances, followed by studies on UCCs while studies on electronic marketplace platforms reported only one market barrier, i.e. low market share of the CTN.

Additionally, a stage-gate decision-making model is developed to guide the CTN implementation by considering the conceptual barrier framework. The proposed model divides the CTN implementation decision-making process into four stages involving scoping, building the business case, developing the CDSS, and operating and maintaining the CTN. The conceptual framework provides knowledge on the barriers relevant to each stage. This knowledge can provide the decision makers with the right base for making the proper decisions at each gate.

The findings of this paper have practical and theoretical contributions. On the theoretical level, the paper contributes to the conceptual understanding of the barriers to CTN implementation. On the practical level, the results provide valuable discussions on the CTN implementation decisionmaking process. This will be useful to logistics service providers, freight carriers, logistics IT developers, researchers, decision makers in the logistics industry, funding organizations, and entrepreneurs in identifying the best practices to maximize the CTN benefits and minimize failure risk.

This research has some limitations. First, the identified barriers were not ranked to indicate their relative importance. Although the ranking of the barriers can be made based on their citation frequency, such ranking might be misleading due to the change in focus on specific barriers in the literature over time. Second, the interlinkages among identified barriers were not considered. Future work should address the limitations of this study: First, the relative importance of identified barriers can be determined through ranking and pairwise comparison techniques such as Delphi and Analytical Hierarchy Process (AHP) techniques. Second, investigating the interactions among the barriers by using causal analysis approaches, e.g., Decision Making Trial and Evaluation Laboratory (DEMATEL), to develop better mitigation strategies. Additionally, quantifying the impacts of different barriers on collaborative freight transport is of great value to be considered through agent-based simulation and modelling approaches. Another potential limitation is that the proposed stage-gate model lacks validation and therefore, an important direction for future research is to validate the proposed stage-gate model by means of several case studies.

\section{Appendix 1: The identified 31 barriers to CTN}

\begin{tabular}{|c|c|c|}
\hline Barrier group & Barrier & Article \\
\hline \multirow[t]{8}{*}{ CTN business model } & Organizational setup & {$[7,23,44]$} \\
\hline & $\begin{array}{l}\text { Operational govern- } \\
\text { ance mode }\end{array}$ & {$[15,21,49,50]$} \\
\hline & Value propositions & {$[16,19,33,44,51]$} \\
\hline & Key resources & {$[10,16,23,52]$} \\
\hline & $\begin{array}{l}\text { Revenue streams and } \\
\text { cost structures }\end{array}$ & {$[16,23,33,44,45]$} \\
\hline & Initiators & {$[45,53]$} \\
\hline & Coordinators & {$[16,23,54-56]$} \\
\hline & Customers & {$[2,7,11,37,41,57]$} \\
\hline \multirow[t]{5}{*}{ Information sharing } & $\begin{array}{l}\text { Incomplete logistics } \\
\text { information }\end{array}$ & [58-61] \\
\hline & $\begin{array}{l}\text { Inefficient information } \\
\text { flow and updates }\end{array}$ & {$[12,28,62,63]$} \\
\hline & $\begin{array}{l}\text { Inaccurate informa- } \\
\text { tion }\end{array}$ & {$[12,39,63,64]$} \\
\hline & $\begin{array}{l}\text { Heterogeneous infor- } \\
\text { mation formats }\end{array}$ & {$[12,34,65,66]$} \\
\hline & Lack of ICT systems & {$[28,63,67,68]$} \\
\hline \multirow[t]{6}{*}{ Human factors } & Experience & {$[28,35,70]$} \\
\hline & Lack of commitment & {$[52,70,71]$} \\
\hline & $\begin{array}{l}\text { Distrust among } \\
\text { partners }\end{array}$ & $\begin{array}{l}{[10,12,32,42,50,70,} \\
72-76]\end{array}$ \\
\hline & Distrust of the CTN & $\begin{array}{l}{[12,31,55,56,70,76,} \\
77]\end{array}$ \\
\hline & $\begin{array}{l}\text { Fears of changing } \\
\text { their business model }\end{array}$ & {$[70,78,79]$} \\
\hline & $\begin{array}{l}\text { Unawareness of col- } \\
\text { laboration benefits }\end{array}$ & {$[69,70,78,80]$} \\
\hline \multirow[t]{6}{*}{ CDSSS } & $\begin{array}{l}\text { Cost/profit-sharing } \\
\text { mechanism }\end{array}$ & {$[5,9,81-86]$} \\
\hline & $\begin{array}{l}\text { Plenty of collaborative } \\
\text { proposals }\end{array}$ & {$[28,39,58,87,88]$} \\
\hline & $\begin{array}{l}\text { Collaborative plan- } \\
\text { ning algorithms }\end{array}$ & {$[8,28,40,62,107]$} \\
\hline & $\begin{array}{l}\text { Evaluation of collabo- } \\
\text { rating proposals }\end{array}$ & {$[4,5,89,108]$} \\
\hline & $\begin{array}{l}\text { Lack of interactive } \\
\text { communication tools }\end{array}$ & {$[22,28,34,90]$} \\
\hline & $\begin{array}{l}\text { Lack of system inte- } \\
\text { gration }\end{array}$ & {$[57,63,91,92]$} \\
\hline \multirow[t]{5}{*}{ Market } & Regulations & {$[38,69,93]$} \\
\hline & Vertical integration & {$[7,36,37]$} \\
\hline & $\begin{array}{l}\text { Imbalanced freight } \\
\text { flows }\end{array}$ & {$[45,61,70,94]$} \\
\hline & $\begin{array}{l}\text { Low market share of } \\
\text { the CTN }\end{array}$ & {$[20,27,95,96]$} \\
\hline & $\begin{array}{l}\text { No Public incentives } \\
\text { for collaboration }\end{array}$ & {$[45,78,94,97]$} \\
\hline
\end{tabular}




\section{Appendix 2: The Benefits of CTN discussed in the literature}

\begin{tabular}{ll}
\hline Benefits & Article \\
\hline Better service level & {$[4,31,84,109]$} \\
Low transport cost & {$[3,28,31,83,108,110,111]$} \\
Less carbon emissions & {$[3,26,112-114]$} \\
Less empty running & {$[6,74,115,116]$} \\
Less traffic congestion & {$[4,8,43,111,117,118]$} \\
Shorter delivery times & {$[86,119]$} \\
Higher resource utilization & {$[29,34,116]$} \\
Shorter lead times & {$[29,84]$} \\
More flexibility & {$[30,38,109]$} \\
New knowledge & {$[70,84,102]$} \\
Access to new market & {$[70,84,120,121]$} \\
\hline
\end{tabular}

Acknowledgements

None.

\section{Authors' contributions}

AK conceptualized the research and created the suitable methodology. AK conducted the review and was responsible for the graphical representation of the results. AK, KR, and CØ explained the findings. In paper writing, all authors participated. The author(s) read and approved the final manuscript.

\section{Funding}

This research was done as part of the DiRECTLY project (6156-00001B) funded by Innovation Fund Denmarks Grand Solution scheme. Open Access funding provided by the DiRECTLY project (6156-00001B).

\section{Availability of data and materials}

The search queries used in Scopus and WoS during the study are available from the corresponding authors on reasonable requests.

\section{Declaration}

\section{Competing interests}

The authors declare that they have no competing interests.

\section{Author details}

'Department of the Built Environment, Aalborg University, Aalborg, Denmark. ${ }^{2}$ Mechanical Engineering Department, Faculty of Engineering at Shoubra, Benha University, Cairo, Egypt. ${ }^{3}$ Aalborg University Business School, Aalborg, Denmark.

Received: 18 February 2021 Accepted: 3 September 2021 Published: 20 September 2021

\section{References}

1. Eurostat. (2021). Road freight transport by vehicle characteristics. Eurostat.

2. Cruijssen, F., Bräysy, O., Dullaert, W., et al. (2007). Joint route planning under varying market conditions. International Journal of Physical Distribution and Logistics Management, 37, 287-304. https://doi.org/10.1108/ 09600030710752514

3. Karam, A., Tsiulin, S., Reinau, K. H., \& Eltawil, A. (2020). An improved two-level approach for the collaborative freight delivery in urban areas. In: Zhang, J., Dresner, M., Zhang, R., Hua, G., \& Shang, X. (Eds.), LISS2019. Springer, Singapore. 26-29 July, Maryland, USA.

4. Chabot, T., Bouchard, F., Legault-Michaud, A., et al. (2018). Service level, cost and environmental optimization of collaborative transportation.
Transportation Research Part E: Logistics Transportation Review, 110, 1-14. https://doi.org/10.1016/j.tre.2017.11.008

5. Gansterer, M., \& Hartl, R. F. (2020). Shared resources in collaborative vehicle routing. TOP, 28, 1-20. https://doi.org/10.1007/s11750-020-00541-6

6. Ergun, O., Kuyzu, G., \& Savelsbergh, M. (2007). Reducing truckload transportation costs through collaboration. Transportation Science, 41, 206-221. https://doi.org/10.1287/trsc.1060.0169

7. Pan, S., Trentesaux, D., Ballot, E., \& Huang, G. Q. (2019). Horizontal collaborative transport: Survey of solutions and practical implementation issues. International Journal of Production Research, 57, 5340-5361. https://doi.org/10.1080/00207543.2019.1574040

8. Gansterer, M., \& Hartl, R. F. (2018). Collaborative vehicle routing: A survey. European Journal of Operational Research, 268, 1-12.

9. Guajardo, M. \& Rönnqvist, M. (2016). A review on cost allocation methods in collaborative transportation. International Transactions in Operational Research, 23, 371-392. https://doi.org/10.1111/itor.12205

10. Badraoui, I., Van der Vorst, J. G. A., \& Boulaksil, Y. (2020). Horizontal logistics collaboration: An exploratory study in Morocco's agri-food supply chains. International Journal of Logistics Research and Applications, 23, 85-102. https://doi.org/10.1080/13675567.2019.1604646

11. Basso, F., Basso, L. J., Rönnqvist, M., \& Weintraub, A. (2020). Coalition formation in collaborative production and transportation with competing firms. European Journal of Operational Research, 289, 569-581. https:// doi.org/10.1016/j.ejor.2020.07.039

12. Basso, F., D'Amours, S., Rönnqvist, M., \& Weintraub, A. (2019). A survey on obstacles and difficulties of practical implementation of horizontal collaboration in logistics. International Transactions in Operational Research, 26, 775-793. https://doi.org/10.1111/itor.12577

13. Cao, M., \& Zhang, Q. (2011). Supply chain collaboration: Impact on collaborative advantage and firm performance. Journal of Operations Management, 29, 163-180. https://doi.org/10.1016/j.jom.2010.12.008

14. Raweewan, M., \& Ferrell, W. G. (2018). Information sharing in supply chain collaboration. Computers \& Industrial Engineering, 126, 269-281. https://doi.org/10.1016/j.cie.2018.09.042

15. Klaas-Wissing, T., \& Albers, S. (2010). Cooperative versus corporate governance of LTL networks. International Journal of Logistics Research and Applications, 13, 493-506. https://doi.org/10.1080/13675561003776828

16. Björklund, M., Abrahamsson, M., \& Johansson, H. (2017). Critical factors for viable business models for urban consolidation centres. Research in Transportation Economics, 64, 36-47. https://doi.org/10.1016/j.retrec. 2017.09.009

17. Vargas, A., Fuster, C., \& Corne, D. (2020). Towards sustainable collaborative logistics using specialist planning algorithms and a gain-sharing business model: A UK case study. Sustainability, 12, 6627. https://doi. org/10.3390/su12166627

18. Gibson, B. J., Rutner, S. M., \& Keller, S. B. (2002). Shipper-carrier partnership issues, rankings and satisfaction. International Journal of Physical Distribution and Logistics Management, 32, 669-681. https://doi.org/10. 1108/09600030210444917

19. Gonzalez-Feliu, J., Morana, J., Grau, J.-M.S., \& Ma, T.-Y. (2013). Design and scenario assessment for collaborative logistics and freight transport systems. International Journal of Transport Economics, 40, 207-240.

20. Cleophas, C, Cottrill, C. Fabian, J \& Tierney, K. (2019). Collaborative urban transportation : Recent advances in theory and practice. European Journal of Operational Research, 273, 801-816. https://doi.org/10. 1016/j.ejor.2018.04.037

21. Nandiraju, S., \& Regan, A. (2008). Freight transportation electronic marketplaces: A survey of the industry and exploration of important research issues.

22. TIMOCOM. (2020). The market leader among vehicle and freight exchanges. https://www.timocom.co.uk/smart-logistics-system/freig ht-exchange. Accessed 27 Jun 2020.

23. Albers, S., \& Klaas-Wissing, T. (2012). Organisation of multilateral LTL alliances. International Journal of Logistics Research and Applications, 15, 181-198. https://doi.org/10.1080/13675567.2012.709836

24. Soysal, M. Bloemhof-Ruwaard, J. M... Haijema, R. \& van der V. J. G. A. J. (2018). Modeling a green inventory routing problem for perishable products with horizontal collaboration. Computers \& Operations Research.

25. Muñoz-Villamizar, A., Quintero-Araújo, C. L., Montoya-Torres, J. R., \& Faulin, J. (2019). Short- and mid-term evaluation of the use of electric 
vehicles in urban freight transport collaborative networks: A case study. International Journal of Logistics Research and Applications, 22, 229-252. https://doi.org/10.1080/13675567.2018.1513467

26. Ballot, E., \& Fontane, F. (2010). Reducing transportation CO2 emissions through pooling of supply networks: Perspectives from a case study in French retail chains. Production Planning \& Control, 21, 640-650. https:// doi.org/10.1080/09537287.2010.489276

27. Ferrell, W., Ellis, K., Kaminsky, P., et al. (2019). Horizontal collaboration: Opportunities for improved logistics planning. International Journal of Production Research. https://doi.org/10.1080/00207543.2019.1651457

28. Dahl, S., \& Derigs, U. (2011). Cooperative planning in express carrier networks-An empirical study on the effectiveness of a real-time Decision Support System. Decision Support Systems, 51, 620-626. https://doi.org/ 10.1016/j.dss.2011.02.018

29. Agarwal, R., \& Ergun, Ö. (2010). Network design and allocation mechanisms for carrier alliances in liner shipping. Operations Research, 58 1726-1742. https://doi.org/10.1287/opre.1100.0848

30. Lotte V, Katerien R, Greeit KJ (2013) Collaborative Logistics from the Perspective of Road Transportation Companies. Transp Rev 33:700-719. https://doi.org/10.1080/01441647.2013.853706

31. Cruijssen, F., Cools, M., \& Dullaert, W. (2007). Horizontal cooperation in logistics: Opportunities and impediments. Transportation Research Part E Logistics Transportation Review, 43, 129-142. https://doi.org/10.1016/j. tre.2005.09.007

32. Clifton, C., Iyer, A., Cho, R., et al. (2008). An approach to securely identifying beneficial collaboration in decentralized logistics systems. Manufacturing \& Service Operations Management, 10, 108-125. https:// doi.org/10.1287/msom.1070.0167

33. Lin, I. I., Mahmassani, H. S., Jaillet, P., \& Michael Walton, C. (2007). Electronic marketplaces for transportation services: Shipper considerations. Transportation Research Record, 1790, 1-9. https://doi.org/10.3141/ 1790-01

34. Chen, M. C., Yeh, C. T., \& Chen, K. Y. (2010). Development of collaborative transportation management framework with Web Services for TFT-LCD supply chains. International Journal of Computer Integrated Manufacturing, 23, 1-19. https://doi.org/10.1080/09511920903030353

35. Wang, X., \& Kopfer, H. (2014). Collaborative transportation planning of less-than-truckload freight: A route-based request exchange mechanism. OR Spectrum, 36, 357-380. https://doi.org/10.1007/ s00291-013-0331-x

36. Özener, O. Ö., Ergun, Ö., \& Savelsbergh, M. (2011). Lane-exchange mechanisms for truckload carrier collaboration. Transportation Science, 45, 1-17. https://doi.org/10.1287/trsc.1100.0327

37. Yilmaz, O., \& Savasaneril, S. (2012). Collaboration among small shippers in a transportation market. European Journal of Operational Research 218, 408-415. https://doi.org/10.1016/j.jor.2011.11.018

38. Vanovermeire, C., \& Sörensen, K. (2014). Integration of the cost allocation in the optimization of collaborative bundling. Transportation Research Part E Logistics Transportation Review, 72, 125-143. https://doi. org/10.1016/j.tre.2014.09.009

39. Ilie-Zudor, E., Ekárt, A., Kemeny, Z., et al. (2015). Advanced predictiveanalysis-based decision support for collaborative logistics networks. Supply Chain Management, 20, 369-388. https://doi.org/10.1108/ SCM-10-2014-0323

40. Sprenger, R., \& Mönch, L. (2014). A decision support system for cooperative transportation planning: Design, implementation, and performance assessment. Expert Systems with Applications, 41, 5125-5138. https://doi.org/10.1016/j.eswa.2014.02.032

41. Serrano-Hernández, A., Juan, A. A., Faulin, J., \& Perez-Bernabeu, E. (2017). Horizontal collaboration in freight transport: Concepts, benefits, and environmental challenges. SORT, 41, 393-414. https://doi.org/10.2436/ 20.8080.02.65

42. Hribernik, M., Zero, K., Kummer, S., \& Herold, D. M. (2020). City logistics: Towards a blockchain decision framework for collaborative parcel deliveries in micro-hubs. Transportation Research Interdisciplinary Perspectives, 8, 100274. https://doi.org/10.1016/j.trip.2020.100274

43. Simmer, L., Pfoser, S., \& Grabner, M. et al. (2017). From horizontal collaboration to the physical internet—A case study from Austria. International Journal of Transport Development and Integration. WITPress (pp. 129-136).
44. Katsela, K., \& Pålsson, H. (2020). Viable business models for city logistics: Exploring the cost structure and the economy of scale in a Swedish initiative. Research in Transportation Economics. https://doi.org/10.1016/j. retrec.2020.100857

45. Vargas, A., Patel, S., \& Patel, D. (2018). Towards a business model framework to increase collaboration in the freight industry. Logistics, 2, 22 https://doi.org/10.3390/logistics2040022

46. Lachal, J., Revah-Levy, A., Orri, M., \& Moro, M. R. (2017). Metasynthesis: An original method to synthesize qualitative literature in psychiatry. Front Psychiatry, 8, 269. https://doi.org/10.3389/fpsyt.2017.00269

47. Wuni, I. Y., \& Shen, G. Q. (2020). Barriers to the adoption of modular integrated construction: Systematic review and meta-analysis, integrated conceptual framework, and strategies. Journal of Cleaner Production, 249, 119347. https://doi.org/10.1016/i.jclepro.2019.119347

48. Osterwalder, A., Pigneur, Y., \& Tucci, C. L. (2005). Clarifying business models: Origins, present, and future of the concept. Communications of the Association for Information Systems 16:1-25. https://doi.org/10.17705/ 1 cais.01601.

49. Steinicke, S., Wallenburg, C. M., \& Schmoltzi, C. (2012). Governing for innovation in horizontal service cooperations. Journal of Service Management, 23, 279-302. https://doi.org/10.1108/09564231211226141

50. Reuer, J. J., \& Ariño, A. (2007). Strategic alliance contracts: Dimensions and determinants of contractual complexity. Strategic Management Journal, 28, 313-330. https://doi.org/10.1002/smj.581

51. Naesens, K., Pintelon, L., \& Taillieu, T. (2007). A framework for implementing and sustaining trust in horizontal partnerships. Supply Chain Forum, 8, 32-44. https://doi.org/10.1080/16258312.2007.11517174

52. Kwon, I.G., Louis, S., \& Louis, S. (2004). Factors affecting the level of trust and commitment in supply chain relationships. Journal of Supply Chain and Management 4-14.

53. Österle, I., Aditjandra, P.T., Vaghi, C., et al. (2015). The role of a structured stakeholder consultation process within the establishment of a sustainable urban supply chain. Supply Chain Management, 20, 284-299. https://doi.org/10.1108/SCM-05-2014-0149

54. Nextrust. (2018). Nextrust | Pilot Projects. https://nextrust-project.eu/ pilotprojects. Accessed 9 Jul 2020.

55. Verstrepen, S., Cools, M., Cruijssen, F., \& Dullaert, W. (2009). A dynamic framework for managing horizontal cooperation in logistics. International Journal of Logistics Systems and Management, 5, 228. https://doi. org/10.1504/ijlsm.2009.022497

56. Audy, J.-F.J.-F., D'Amours, S., Rönnqvist, M., \& Ronnqvis, M. (2007). Business models for collaborative planning in transportation: An application to wood products. In L. M. Camarinha-Matos, H. Afsarmanesh, P. Novais, \& C. Analide (Eds.), Establishing the foundation of collaborative networks (pp. 667-676). Springer.

57. Kaveh, N., \& Samani, N. K. (2009). How collaborative logistics management increases supply chain efficiency.

58. Chow, H. K. H., Choy, K. L., \& Lee, W. B. (2007). A strategic knowledgebased planning system for freight forwarding industry. Expert Systems with Applications, 33, 936-954. https://doi.org/10.1016/j.eswa.2006.08 004

59. Daudi, M., Hauge, J. B., \& Thoben, K. D. (2016). Behavioral factors influencing partner trust in logistics collaboration: A review. Logistics Research, 9, 1-11. https://doi.org/10.1007/s12159-016-0146-7

60. Zhou, H., \& Benton, W. C. (2007). Supply chain practice and information sharing. Journal of Operations Management, 25, 1348-1365. https://doi. org/10.1016/j.jom.2007.01.009

61. Creemers, S., Woumans, G., Boute, R., \& Beliën, J. (2017). Tri-vizor uses an efficient algorithm to identify collaborative shipping opportunities. Interfaces (Providence), 47, 244-259. https://doi.org/10.1287/inte.2016. 0878

62. Buijs, P., \& Wortmann, J. C. H. (2014). Joint operational decision-making in collaborative transportation networks: The role of IT. Supply Chain Management, 19, 200-210. https://doi.org/10.1108/SCM-08-2013-0298

63. D'Amours, S., \& Rönnqvist, M. (2010). Issues in collaborative logistics. In Energy, natural resources and environmental economics. Springer, Berlin, Heidelberg (pp .395-409).

64. Ghosn, M., \& Moses, F. (2000). Effect of changing truck weight regulations on U.S. Journal of Bridge Engineering, 5, 304-310. https://doi.org/ 10.1061/(asce) 1084-0702(2000)5:4(304) 
65. Fawcett, S. E., Osterhaus, P., Magnan, G. M., et al. (2007). Information sharing and supply chain performance: The role of connectivity and willingness. Supply Chain Management, 12, 358-368. https://doi.org/10. 1108/13598540710776935

66. Liu, D., Roberto Boër, C., Sacco, M., \& Fornasiero, R. (2006). A networked engineering portal to support distributed supply chain partnership. International Journal of Computer Integrated Manufacturing, 19, 91-103. https://doi.org/10.1080/09511920500090354

67. Frehe, V., \& Teuteberg, F. (2017). Information and communication technology in green logistics: Status quo and research gaps. Management Review Quartely, 67, 65-96. https://doi.org/10.1007/s11301-017-0124-4

68. Belzer, M. H. (2002). Technological innovation and the trucking industry: Information revolution and the effect on the work process. Journal of Labor Research, 23, 375-395. https://doi.org/10.1007/ s12122-002-1042-2

69. Cruijssen, F. (2013). Operational and legal framework for collaboration.

70. Lydeka, Z., \& Adomavičius, B. (2007). Cooperation among The Competitors in International Cargo Transportation Sector: Key factors to success. Engineering Economics 51:

71. Tate, K. (1996). The elements of a successful logistics partnership. International Journal of Physical Distribution and Logistics Management, 26, 7-13. https://doi.org/10.1108/09600039610115045

72. Jeng, D. J. F. (2015). Generating a causal model of supply chain collaboration using the fuzzy DEMATEL technique. Computers \& Industrial Engineering, 87, 283-295. https://doi.org/10.1016/j.cie.2015.05.007

73. Barratt, M. (2004). Understanding the meaning of collaboration in the supply chain. Supply Chain Management, 9, 30-42. https://doi.org/10. 1108/13598540410517566

74. Islam, S., Shi, Y., Ahmed, J. U., \& Uddin, M. J. (2019). Minimization of empty container truck trips: Insights into truck-sharing constraints. International Journal of Logistics Management, 30, 641-662. https://doi. org/10.1108/IJLM-08-2018-0191

75. Los, J., Schulte, F., Spaan, M. T. J., \& Negenborn, R. R. (2020). The value of information sharing for platform-based collaborative vehicle routing. Transportation Research Part E Logistics Transportation Review, 141, 102011. https://doi.org/10.1016/j.tre.2020.102011

76. Baron, R., Zieris, M., Zintel, M., \& Mikulla, D. (2017). Digital platforms in freight transportation.

77. Cruijssen, F., Borm, P., Fleuren, H., \& Hamers, H. (2010). Supplier-initiated outsourcing: A methodology to exploit synergy in transportation. European Journal of Operational Research, 207, 763-774. https://doi.org/ 10.1016/j.ejor.2010.06.009

78. Paddeu, D., Parkhurst, G., Fancello, G., et al. (2018). Multi-stakeholder collaboration in urban freight consolidation schemes: Drivers and barriers to implementation. Transport, 33, 913-929. https://doi.org/10.3846/ transport.2018.6593

79. Ghosh, A., \& Morita, H. (2012). Competitor collaboration and product distinctiveness. International Journal of Industrial Organization, 30, 137-152. https://doi.org/10.1016/j.ijindorg.2011.07.003

80. Kale, R., Evers, P. T., \& Dresner, M. E. (2007). Analyzing private communities on Internet-based collaborative transportation networks. Transportation Research Part E Logistics Transportation Review, 43, 21-38. https:// doi.org/10.1016/j.tre.2005.07.004

81. Audy, J. F., Lehoux, N., D'Amours, S., \& Rönnqvist, M. (2012). A framework for an efficient implementation of logistics collaborations. International Transactions in Operational Research, 19, 633-657. https://doi.org/10. 1111/j.1475-3995.2010.00799.x

82. Frisk, M., Göthe-Lundgren, M., Jörnsten, K., \& Rönnqvist, M. (2010). Cost allocation in collaborative forest transportation. European Journal of Operational Research, 205, 448-458. https://doi.org/10.1016/j.ejor.2010. 01.015

83. Flisberg, P., Frisk, M., Rönnqvist, M., \& Guajardo, M. (2015). Potential savings and cost allocations for forest fuel transportation in Sweden: A country-wide study. Energy, 85, 353-365. https://doi.org/10.1016/j. energy.2015.03.105

84. Schmoltzi, C., \& Marcus Wallenburg, C. (2011). Horizontal cooperations between logistics service providers: Motives, structure, performance. International Journal of Physical Distribution and Logistics Management, 41,552-575. https://doi.org/10.1108/09600031111147817

85. McKinnon, A. (2017). Sustainable logistics: Switching to alternative energy sources. Lectures Notes Logistics (pp. 1-27).
86. Audy, J. F., D'Amours, S. (2008). Impact of benefit sharing among companies in the implantation of a collaborative transportation systemAn application in the furniture industry. In: IFIP International Federation for Information Processing. Springer, Boston, MA (pp. 519-532).

87. Tools, T. (2019). Trucker tools: Digital load tracking \& freight matching. In Truck. Tools Digit. Load Track. Freight Matching. https://www.truckertoo Is.com/web/. Accessed 17 Jul 2020.

88. Buijs, P., Lopez Alvarez, J. A., Veenstra, M., \& Roodbergen, K. J. (2016). Improved collaborative transport planning at Dutch logistics service provider fritom. Interfaces (Providence), 46, 119-132. https://doi.org/10. 1287/inte.2015.0838

89. Lockridge, D. (2019). Technology is Changing how carriers, shippers, and brokers connect. In: Technol. is Chang. How Carriers, Shipp. Brokers Connect. https://www.truckinginfo.com/336365/technology-is-chang ing-how-carriers-shippers-and-brokers-connect. Accessed 17 Jul 2020.

90. Eriksson, J., \& Rönnqvist, M. (2003). Transportation and route planning: Åkarweb-A web-based planning system. In Proceedings of the second forest engineering conference. 12-15 May, Växjö, Sweden (pp. 48-57).

91. Lieb, R., \& Miller, J. (2002). The use of third-party logistics services by large US manufacturers, the 2000 survey. International Journal of Logistics Research and Applications, 5, 1-12. https://doi.org/10.1080/13675 560110114270

92. Piplani, R., Pokharel, S., \& Tan, A. (2004). Perspectives on the use of information technology at third party logistics service providers in Singapore. Asia Pacific Journal of Marketing and Logistics, 16, 27-41. https:// doi.org/10.1108/13555850410765113

93. The Council of the European Union Commission. (2013). Rules Applicable to Antitrust Enforcement: Volume I.

94. White, M., Willis, S., \& Douglas, C. (2017). Freight Industry Collaboration Study.

95. Li, Y., \& Yu, Y. (2017). The use of freight apps in road freight transport for CO2 reduction. European Transport Research Review, 9, 1-13. https://doi. org/10.1007/s12544-017-0251-y

96. Singh, S. (2015). The disruption uber has brought to the taxi business is coming to trucking. https://www.forbes.com/sites/sarwantsingh/2015/ 08/03/uber-taxi-truck/?sh=125cf0257f6d. Accessed 7 Jun 2021.

97. Cruijssen, F. (2020). Cross-Chain Collaboration in Logistics. Springer International Publishing.

98. Sumner, W. (2008). Overcoming barriers to collaboration: Creating a successful collaborative supply chain. Supply Demand Chain Exec.

99. The Council of the European Union. (2009). Council Regulation (EC) No 169/2009 of 26 February 2009 applying rules of competition to transport by rail, road and inland waterway. Official Journal of the European Union, 61, 1-5.

100. Castro, J., \& Kuse, H. (2005). Impacts of large truck restrictions in freight carrier operations in metro manila. Journal of the Eastern Asia Society for Transportation Studies 6, 2947-2962. https://doi.org/10.11175/easts.6. 2947.

101. van Duin, J. H. R., van Kolck, A., Anand, N., et al. (2012). Towards an agent-based modelling approach for the evaluation of dynamic usage of urban distribution centres. Procedia - Social and Behavioral Sciences, 39, 333-348. https://doi.org/10.1016/j.sbspro.2012.03.112

102. Sakakibara, M. (1997). Heterogeneity of firm capabilities and cooperative research and development: An empirical examination of motives. Strategic Management Journal, 18, 143-164.

103. Fawcett, S. E., Magnan, G. M., \& McCarter, M. W. (2008). A three-stage implementation model for supply chain collaboration. Journal of Business Logistics, 29, 93-112. https://doi.org/10.1002/j.2158-1592.2008. tb00070.x

104. Bhattacharjee, D., \& Mohanty, R. P. (2012). Towards development of composite supply chain collaboration model. International Journal of Logistics Systems and Managementnt, 12, 123-147. https://doi.org/10. 1504/IJLSM.2012.047218

105. Cooper, R. G. (1990). Stage-gate systems: A new tool for managing new products. Business Horizons, 33, 44-54.

106. Jagoda, K., \& Samaranayake, P. (2017). An integrated framework for ERP system implementation. International Journal of Accounting and Information Management, 25, 91-109.

107. Berger, S., \& Bierwirth, C. (2010). Solutions to the request reassignment problem in collaborative carrier networks. Transportation Research Part 
E Logistics Transportation Review, 46, 627-638. https://doi.org/10.1016/j. tre.2009.12.006

108. Soysal, M., Bloemhof-Ruwaard, J. M., Haijema, R., \& van der Vorst, J. G. A. J. (2018). Modeling a green inventory routing problem for perishable products with horizontal collaboration. Computers \& Operation Research, 89, 168-182. https://doi.org/10.1016/j.cor.2016.02.003

109. Lehoux, N., Damours, S., \& Langevin, A. (2014). Inter-firm collaborations and supply chain coordination: Review of key elements and case study. Production Planning \& Control, 25, 858-872. https://doi.org/10.1080/ 09537287.2013 .771413

110. Wang, X., Kopfer, H., \& Gendreau, M. (2014). Operational transportation planning of freight forwarding companies in horizontal coalitions. European Journal of Operational Research, 237, 1133-1141. https://doi. org/10.1016/j.ejor.2014.02.056

111. Montoya-Torres, J. R., Muñoz-Villamizar, A., \& Vega-Mejía, C. A. (2016). On the impact of collaborative strategies for goods delivery in city logistics. Production Planning \& Control, 27, 443-455. https://doi.org/10.1080/ 09537287.2016.1147092

112. Pan, S., Ballot, E., \& Fontane, F. (2013). The reduction of greenhouse gas emissions from freight transport by pooling supply chains Int. J. Production Economics The reduction of greenhouse gas emissions from freight transport by pooling supply chains. International Journal of Production Economics, 143, 86-94. https://doi.org/10.1016/j.ijpe.2010.10. 023

113. Pérez-Bernabeu, E., Juan, A. A., Faulin, J., \& Barrios, B. B. (2015). Horizontal cooperation in road transportation: A case illustrating savings in distances and greenhouse gas emissions. International Transactions in Operational Research, 22, 585-606. https://doi.org/10.1111/itor.12130

114. Browne, M., Allen, J., \& Leonardi, J. (2011). Evaluating the use of an urban consolidation centre and electric vehicles in central London. IATSS Research, 35, 1-6. https://doi.org/10.1016/j.iatssr.2011.06.002

115. Hernández, S., \& Peeta, S. (2011). Centralized time-dependent multiplecarrier collaboration problem for less-than-truckload carriers. Transportation Research Record, 2263, 26-34. https://doi.org/10.3141/2263-04

116. Dai, B., \& Chen, H. (2012). Profit allocation mechanisms for carrier collaboration in pickup and delivery service. Computers \& Industrial Engineering, 62, 633-643. https://doi.org/10.1016/j.cie.2011.11.029

117. Allen, J., Browne, M., Woodburn, A., \& Leonardi, J. (2014). A review of urban consolidation centres in the supply chain based on a case study approach. Supply Chain Forum, 15, 100-112. https://doi.org/10.1080/ 16258312.2014.11517361

118. Azab, A., Karam, A., Eltawil, A., et al. (2019). A simulation-based optimization approach for external trucks appointment scheduling in container terminals scheduling in container terminals. International Journal of Modelling and Simulation, 00, 1-18. https://doi.org/10.1080/02286203. 2019.1615261

119. Singh, H., Garg, R. K., \& Sachdeva, A. (2018). Supply chain collaboration: A state-of-the-art literature review. Uncertainity Supply Chain Management, 6, 149-180. https://doi.org/10.5267/j.uscm.2017.8.002

120. Glaister, K. W., \& Buckley, P. J. (1996). Strategic motives for international alliance formation. Journal of Management Studies, 33, 301-332. https:// doi.org/10.1111/j.1467-6486.1996.tb00804.x

121. Gulati, R., \& Singh, H. (1998). The architecture of cooperation: Managing coordination costs and appropriation concerns in strategic alliances. Administrative Science Quarterly, 43, 781-814. https://doi.org/10.2307/ 2393616

122. Karam, A., Reinau, K.H., \& Østergaard, C.R. (2021). Towards a Collaborative Decision Support System for the Freight Transport: a Pilot Test-Based Analysis. IFAC-PapersOnLine, 54, 342-347. https://doi.org/10. 1016/J.IFACOL.2021.06.040

\section{Publisher's Note}

Springer Nature remains neutral with regard to jurisdictional claims in published maps and institutional affiliations.

\section{Submit your manuscript to a SpringerOpen ${ }^{\circ}$ journal and benefit from:}

- Convenient online submission

- Rigorous peer review

- Open access: articles freely available online

- High visibility within the field

- Retaining the copyright to your article

Submit your next manuscript at $\boldsymbol{\nabla}$ springeropen.com 